\title{
Paris in Niue \\ An Analysis of the Aid Effectiveness Agenda in Niue
}

by

\section{Felicia Pihigia Talagi}

A thesis submitted as partial fulfilment of the

Master of Development Studies

School of Geography, Environment and Earth Sciences Victoria

University of Wellington

March, 2017 


\begin{abstract}
The rise of critical thinking about aid and aid effectiveness has shifted development practice towards promoting an active role for aid recipients in their development. The Paris Declaration on aid effectiveness and the five principles for effective aid sits at the core of this development agenda. The aim of this study is to investigate how the aid effectiveness agenda has influenced Niue's development policy and practice. The Government of Niue aspires to be financially self-sufficient. It is an ambitious goal for a small nation that is heavily reliant on aid from the Government of New Zealand. Using primary and secondary sources the results suggested that the Government of Niue asserts a moderate level of effectiveness. To further improve and strengthen the delivery of services the Niue Government undertook a transformation process of the public sector. The major change resulting from this transformation was the amalgamation of over fifteen different departments into five ministries with an added layer of management. The transformation had not yielded the expected results at the time of the research but it has uncovered critical areas for the government to strengthen. These are capacity constraints within the public service, a requirement for a coordinated approach for communication internally and externally, harmonisation of development efforts, transparency and accountability, and the political backing to achieve it all. The New Zealand assistance to the Government of Niue is also analysed using the principles of the Paris Declaration. The results indicated a positive change, considerable improvements from the historical dominating tactics experienced in earlier days. The relationship between the two governments is now recognised as a partnership. The flexibility and the clear communication and dialogue has solidified the partnership which has given confidence and certainty for the Government of Niue to work towards its goal of a prosperous Niue.
\end{abstract}




\section{ACKNOWLEDGEMENTS}

Liuaki atu kia Ia e tau nava moe tau fakaheke ke he tau monuina oti kua foaki mai.

I would like to thank all the people who gave their time and shared their stories with me for the completion of this thesis. To Professor John Overton for your guidance and patience. Thank you for ever being so encouraging even in the lowest of times. To all my Development Studies friends thank you for all the support and coffee dates.

I acknowledge and dedicate this thesis to my wonderful parents Harkai and Nika for instilling in me the importance of education. Thank you for your tireless efforts in making sure that we were given the best. To my siblings Vini, Nita, Umi, Nisi and Ash for your cheers and the daily doses of laughter. You guys are the best. To all my Wellington family from Newlands, Johnsonville, Thorndon, Glenmore and Miramar, you all are wonderful. I would also like to acknowledge the late Rev Aifolia Poumale who sadly left halfway through this journey, I will always remember your teachings. And to all my families who have supported me, my Pihigia, Ikimotu, Tamate, and Talagi fakaaue lahi mahaki.

To my little gems Khanden and Kensei, you are my inspiration, you are my happiness and I thank God every day for giving me you two. Finally to my dearest husband Tene, thank you for standing by me. Words are not enough to express how thankful and grateful I am for your love.

Fakaaue lahi oue tulou. 


\section{ACRONYMS}

$\begin{array}{ll}\text { ADB } & \text { Asia Development Bank } \\ \text { CSOs } & \text { Civil Society Organisations } \\ \text { DAC } & \text { Development Assistance Committee } \\ \text { EPDSU } & \text { Economic, Planning and Development \& Statistics Unit } \\ \text { GON } & \text { Government of Niue } \\ \text { HLF } & \text { High Level Forum } \\ \text { JCFD } & \text { Joint Commitment Framework for Development } \\ \text { KM } & \text { Kilometres } \\ \text { MDGs } & \text { Millennium Development Goals } \\ \text { MFAT } & \text { Ministry of Foreign Affairs and Trade } \\ \text { NISP } & \text { Niue Island Strategic Plan } \\ \text { NNSP } & \text { Niue National Strategic Plan } \\ \text { NZAID } & \text { New Zealand } \\ \text { NZD } & \text { New Zealand Dollar } \\ \text { ODA } & \text { Official Development Assistance } \\ \text { OECD } & \text { Organisation for Economic Co-operation and Development } \\ \text { PACC } & \text { Pacific Adaptation to Climate Change } \\ \text { PEFA } & \text { Public Expenditure and Financial Accountability } \\ \text { PICS } & \text { Pacific Island Countries } \\ \text { PIFS } & \text { Pacific Islands Forum Secretariat } \\ \text { SAPS } & \text { Structural Adjustment Programmes } \\ \text { UN } & \text { United Nations } \\ \text { UNESCO } & \text { United Nations Educational, Scientific and Cultural } \\ \text { UNDP } & \text { Organisation } \\ \text { USA } & \text { United Nations Development Programme } \\ \text { USD } & \text { United States of America } \\ & \text { United States Dollar } \\ & \end{array}$




\section{CONTENTS}

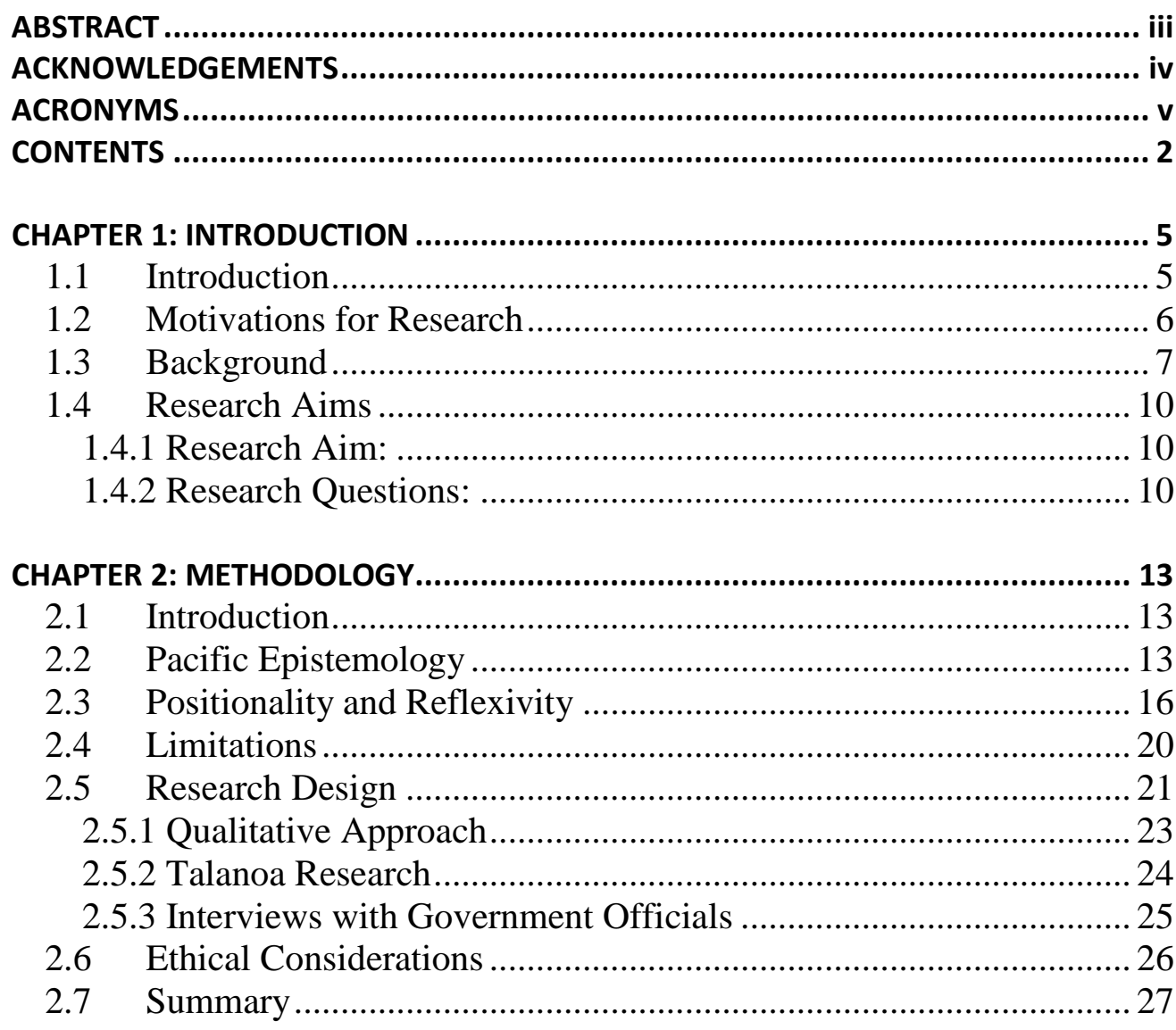

CHAPTER 3: NIUE AND ITS RELATIONSHIP WITH NEW ZEALAND ....................... 28

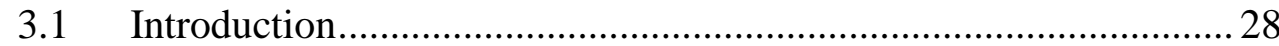

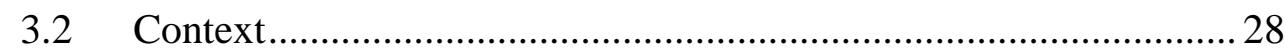

3.2.1 Colonisation and decolonisation................................................ 29

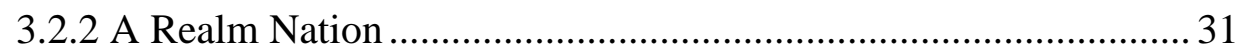

3.2.3 Strategic Development ............................................................. 34

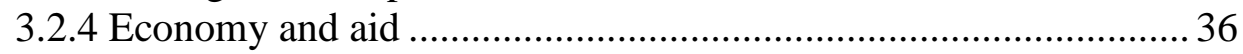

3.2.5 Transformation of Public Sector................................................... 41

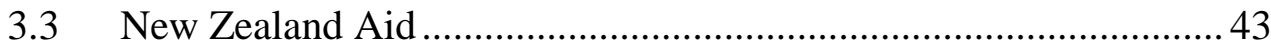

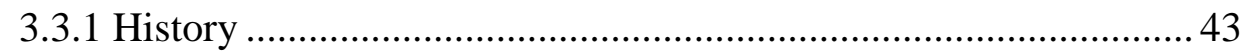

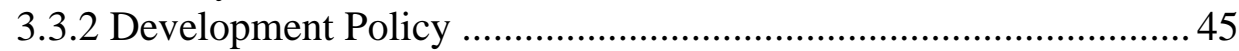

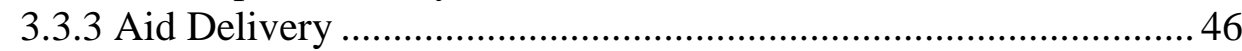

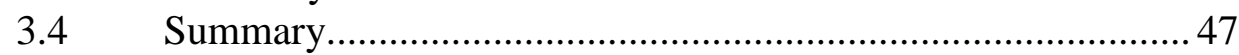

CHAPTER 4: GLOBAL AND REGIONAL DEVELOPMENT POLICY PARADIGM ........... 48

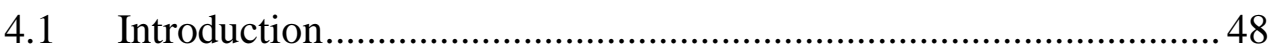

4.2 Aid Thinking and Development Policy ........................................ 48

4.2.1 What, Who, Whom and Why Aid ...............................................50

4.3 High Level Forums for Aid .............................................................. 53

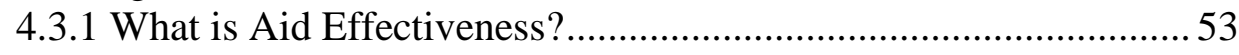

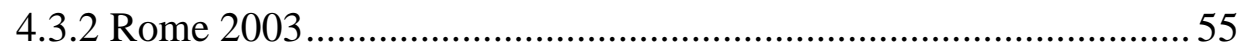

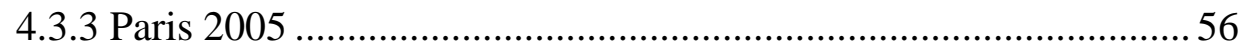


4.3.4 Accra 2008

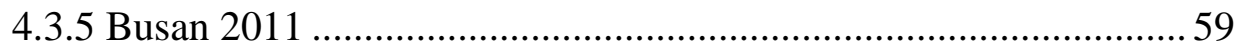

4.4 Pacific Islands and the Aid Effectiveness Agenda ........................59

4.4.1 Pacific Plan for Strengthening Regional Cooperation and Integration

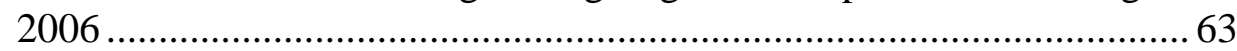

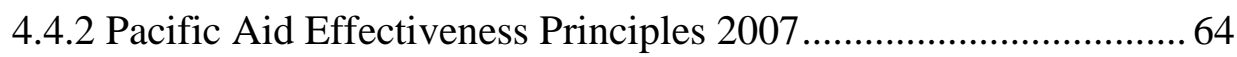

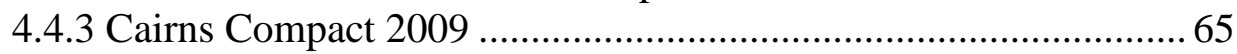

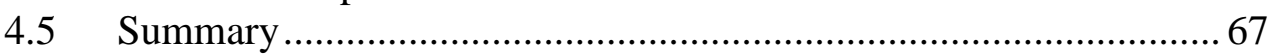

CHAPTER 5: IMPLEMENTING THE AID EFFECTIVENESS AGENDA IN NIUE.............68

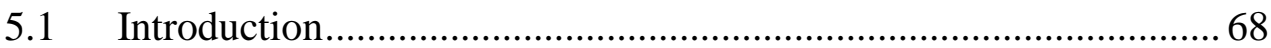

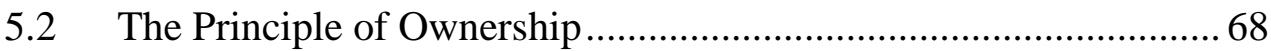

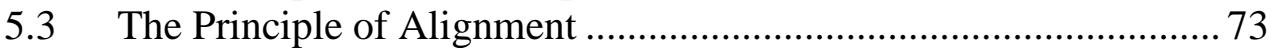

5.4 The Principle of Harmonisation........................................................ 75

5.5 The Principle of Mutual Accountability …..................................... 77

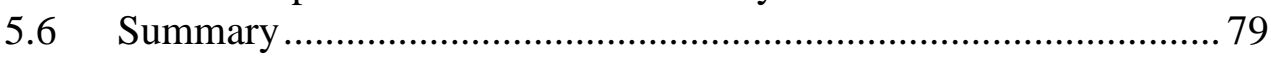

CHAPTER 6: ISSUES AND CHALLENGES OF THE GOVERNMENT...........................81 81

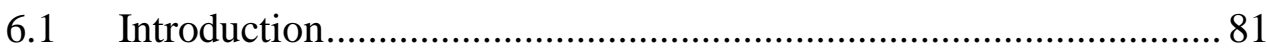

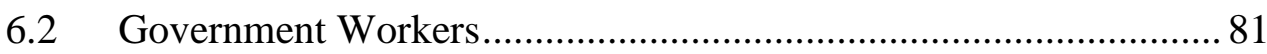

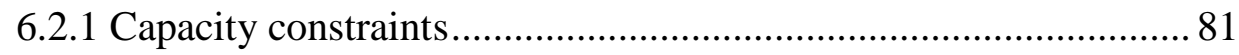

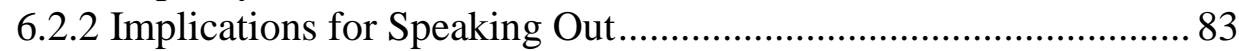

6.2.3 Vested Interests and Behaviour ................................................... 84

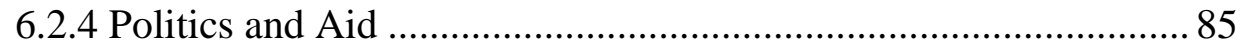

6.3 Government Transformation Process .............................................. 87

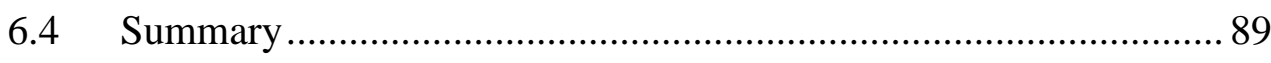

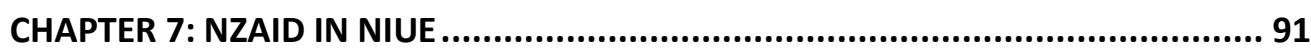

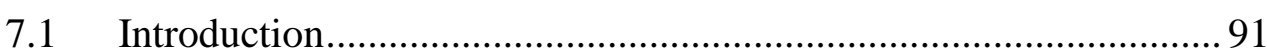

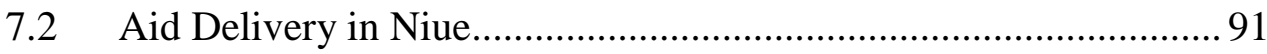

7.2.1 The Joint Commitment Framework for Development .................. 92

7.2.2 The Forward Aid Programme ....................................................... 94

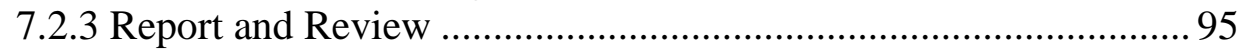

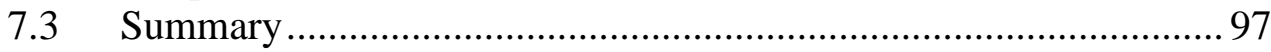

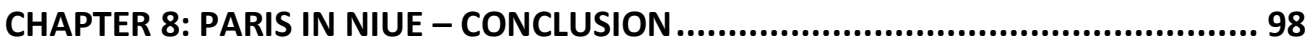

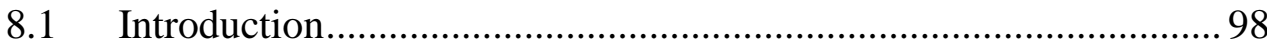

8.2 (Im) Proving Paris in Niue ........................................................ 99

8.3 Next Steps for the Government of Niue ...................................... 100

8.3.1 Manage department relations...................................................... 100

8.3.2 Foster Recipien t-government Led Forums ................................ 101

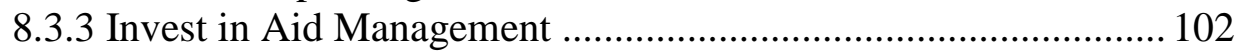

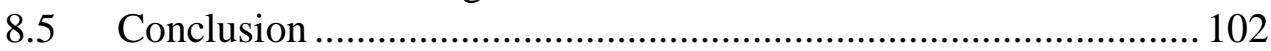

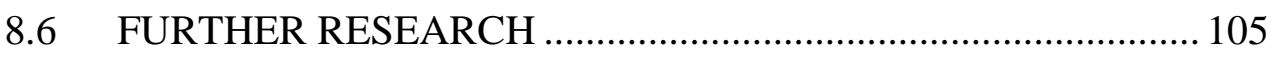

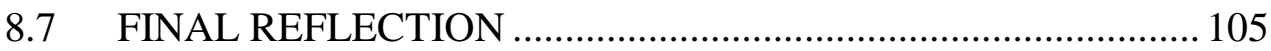


APPENDIX ONE - Interview Guide..

107

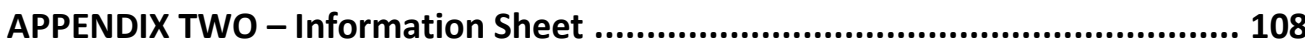

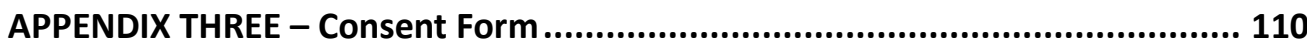

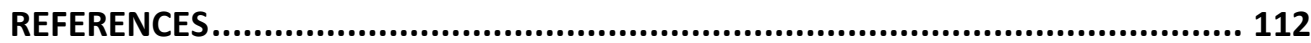




\section{CHAPTER 1: INTRODUCTION}

\subsection{Introduction}

"I participated actively in its propagation" was one line that resonated with me when I first read Epeli Hau'ofa's 'A Sea of Islands' (Hau’ofa, 1993, p150). This very inspiring and thought-provoking article made me think critically about Pasifika bounty and bounds. Hau'ofa discusses the power of perception with regard to Oceania/Pacific and the West's view of the islands using a neocolonial construct and failing to recognise the cultural, historical and the spiritual wealth of Oceania people.

The Pacific has been labelled as one of the most aid-dependent regions in the world, a fact that most islands cannot escape. Aid practice and theory were heavily influenced by modernisation theories which suggested that poor countries could be modernised with the help of rich countries. Modern and rich countries provided the model and resources and led the strategies for the development of poorer countries. This idea of modernisation was the blueprint for any country's development, and it excluded the cultural and historical richness of islands: an idea that I was 'actively propagating'.

The rise of critical thinking about aid and aid effectiveness suggested that the different approaches and requirements of modernisation were only creating more problems and exacerbating existing problems for developing nations. The development agenda has now shifted towards promoting a more active role of aid recipients in their development. The Paris Declaration on aid effectiveness and its principles for smart aid sits at the core of this development 
agenda. This research seeks to understand how the aid effectiveness agenda has influenced development policy and practice in Niue.

\subsection{Motivations for Research}

The Pacific and its oceanic expanse form a minority in terms of world populations, yet it is one of the largest and most desired regions of the world. Australian economist Helen Hughes and her views of Pacific island societies are partially the motivation for this research. Hughes was critical of many features of Pacific societies such as communal land ownership which she suggested acts as a barrier to entrepreneurship and she argued that land should be individualised (Hughes, 2003). The leaders of the Pacific Islands were accused of pursuing their own self-interest at the expense of ordinary people, yet very little was said about the self-interest of the development donors. Hughes decided that the best thing for the Pacific Islands is for donors to cut aid altogether, because aid goes to a government that attracts investment to unproductive initiatives, which encourages people in recipient governments to compete for control therefore breeding corruption. Nevertheless, Hughes was accurate about one thing: only the Pacific people can take charge of their own futures and such change can only come in the Pacific from Pacific initiatives.

I would also like to share an occasion where I attended a seminar of young geographers and a speaker presented on aid in the Pacific highlighting Niue as a case study being heavily dependent on New Zealand aid, and I vividly remember the words of the presenter saying 'Niue is not viable'. Being young 
and naive, I brushed it off at the time but this angers me now because it further adds to this active propagation on my behalf as I did not challenge such views then.

Therefore, in this context it is my motivation to decolonise the Western, neoliberal free market interpretations of Pacific development such as those of Helen Hughes. I believe that there is more to development in the Pacific than the bottom line with dollar signs and we must allow the Pacific people to find their own solutions appropriate to their own conditions.

\subsection{Background}

The international aid system began following the Second World War, and progressed during the Cold War from the 1960s to the 1980s (Lancaster, 2007). At the end of the Cold War the focus of official aid was engaged in poverty alleviation and the promotion of development. Official development aid (ODA), defined by the Development Assistance Committee (DAC) of the Organisation for Economic Co-operation and Development (OECD), is the term used to measure aid. ODA has evolved over the decades, and recently has been criticised for being an inappropriate way of helping developing nations (OECD, 2012; Moyo, 2009).

In response to these criticisms, in recent decades the focus shifted towards aid effectiveness emphasising discourses of participation and partnerships. The international development communities formulated principles towards effective aid beginning with the Rome Declaration for harmonisation, the

Paris Declaration on aid effectiveness, the Accra Agenda for Action and the 
Busan partnership for effective development cooperation in 2003, 2005, 2008 and 2011 respectively.

Emphasis in this research is on the second high level forum in Paris 2005, a significant forum marking the first time donors and recipients both agreed on commitments and holding each other accountable for these (OECD, 2008). The Paris principles of aid effectiveness became central to aid relationships over the following decade.

The Pacific has responded to the aid effectiveness agenda by developing its 'Pacific Aid Effectiveness Principles' adopted in 2007 and tailored to fit the Pacific context (PIFS, 2007). Pacific countries have long been recipients of development aid, whether has achieved the desired outcomes with development partners or not. Recent literature discusses the ability or the inability of small island developing states and their capacity to cope with the demands from development partners. The new aid strategies, supposedly to give greater ownership have pressured and burdened the recipients (Overton, 2012; Goldsmith, 2015).

This can reinforce the Western perception of the Pacific as small, poorly endowed with resources and too isolated from the centres of economic growth to be able to rise beyond its dependence on the largesse of wealthy nations (Hau'ofa, 1993). On the other hand, Gegeo (2002) asserts that development donors need to understand, not ignore, the humanistic aspects and the importance and significance of traditional cultures to national development. $\mathrm{He}$ further reaffirms that development needs to move beyond classic modernisation theory, which emphasises the large-scale, top down, and 
centre-periphery economic initiatives. Instead simple strong family ties or clan ties form an effective social safety net and promote well-being (PIFS, 2005). The Pacific Aid Effectiveness Principles have been adopted by Leaders of the Pacific, however it seems there is disconnect between policy and practice. This research aims to address this gap.

Aid effectiveness is about value for money - it is about managing aid in a way that maximises its impact on development. Donors and developing countries have made many commitments to their own taxpayers and to each other for progress on development. Aid effectiveness is about delivering on those commitments (OECD, 2011).

It has been long debated that there is tension between the variety of development partners delivering aid assistance in a consultative and participatory manner and the recipient country's ability to absorb the assistance offered (PIFS, 2005). The issue of aid effectiveness has re-emerged over the last few years as donors and recipients continue to seek ways to make aid more accountable and to improve delivery approaches. Globally, the international community has signed up to three agreements to enhance aid effectiveness - the Paris Principles (2005), the Accra Agenda for Action (2008) and the Busan Partnership for Effective Development Cooperation (2011). In addition to these, PICs have also agreed on three other important regional mechanisms - the Pacific Plan for strengthening regional cooperation and integration (2006), the Pacific Aid Effectiveness Principles (2007) and the Cairns Compact on strengthening development coordination in the Pacific (2009). These provide the policy foundations for this research. 


\subsection{Research Aims}

\subsubsection{Research Aim:}

The aim of this study is to investigate the influence of the aid effectiveness agenda in Niue's development and vision for a prosperous nation.

\subsubsection{Research Questions:}

1. To what extent are the Paris Declaration Principles of ownership, alignment, harmonisation and mutual accountability practiced in Niue?

2. How effectively does the NZAID programme apply the Paris Declaration principles in its relationship with Niue?

3. What ways can the Government of Niue improve or strengthen its aid relationships internally and externally?

\subsection{Thesis Structure}

This thesis will analyse the challenges encountered by the government officials of Niue in working with the systems surrounding the New Zealand aid programme. The findings of this research will inform the debates surrounding the aid effectiveness agenda. It will hopefully assist the Government of Niue and other Pacific Island countries within similar contexts.

Chapter 2 will discuss the methods I will use to undertake my research. I will discuss my positionality within the research contexts and share some of 
the challenges of doing research within a community that I am familiar with. I will also discuss the importance of Pacific epistemology and how it shapes my research.

Chapter 3 will begin by providing the theoretical background for this research focusing on Niue, New Zealand and the Pacific. I will provide a history of Niue and its journey to self-government highlighting its relationship with New Zealand. I will also provide a brief overview of New Zealand's development policy and the shifts it has undergone.

Chapter 4 will introduce the literature surrounding the aid effectiveness agenda globally focusing particularly on the Paris Declaration and the principles of ownership, alignment, harmonisation and mutual accountability. This is undertaken in order to place this research within the appropriate theoretical context. I will conclude with the mechanisms and strategies the Pacific region as a whole have executed in its work towards effective aid.

Chapter 5 is the first of the three chapters where I will describe the responses of government officials in Niue. This is where I will begin to answer the subquestions of the extent the principles of the Paris Declaration are practiced within Government of Niue departments. The focus is primarily on the departments and what extent the Paris Principles are practiced. 
Chapter 6 will specifically highlight the issues and challenges the government officials shared that have hampered aid and development in Niue.

Chapter 7 will focus entirely on the NZAID programme and the views presented by the government officials. This chapter will also present features that were established by the Ministry of Foreign Affairs and Trade, New Zealand to strengthen the relationship with the Government of Niue.

Chapter 8 will bring together the findings outlined in chapters 5, 6 and 7. I will situate Niue in this big picture: how everything is filtered or supposed to be filtered down to country level. The relationship of Niue with New Zealand will be assessed and see how each complements or contradicts each other's development policies and strategies. 


\section{CHAPTER 2: METHODOLOGY}

\subsection{Introduction}

There are a number of methodologies that have influenced this thesis and so this chapter will outline the methods used and the influences of selecting a Pacific epistemology for research. Studies about the Pacific have been influenced by Western thinking, and although knowledge of the Pacific is taught in a Western setting there needs to be a combination of academia and cultures of the Pacific that truly reflects the Pacific. This research will illustrate a Pacific epistemology in formulating an appropriate methodology. I have used the approach of combining Western and Pacific epistemologies suggested by Thaman (2003).

\subsection{Pacific Epistemology}

Tuhiwai-Smith (1997) poses critical questions for researchers such as 'whose research is it? Who owns it? Whose interests does it serve? Who will benefit from it?' This puts into perspective Pacific epistemology and these necessitates examining the underlying epistemologies of research. Gegeo (2001) refers to epistemology as the theory of knowledge and understanding this knowledge. Knowledge is not the same as a theory of knowledge; just as interpreting an aspect of culture is not the same as exploring people's epistemology. When outside researchers write ethnographies of other people's knowledge's and culture they are creating an epistemological community. It is important to remember that it is not the epistemological community that has created this knowledge. The people's cultures are not 
indigenous theories of those cultures. Instead it has been scrutinised within the Western forms of research, reasoning and interpretation (Gegeo, 2001). Indigenous ethnic groups around the world are asserting their own way of knowing and being, in resistance to the hegemony of mainstream epistemology (Gegeo and Watson-Gegeo, 2001). There is now a strong push for Pacific methodologies and alternative paradigms of knowledge that are appropriate in Pacific context and are outside of the mainstream development methodologies. Thaman (2003) talks about decolonizing Pacific studies and the importance of this referring to the recognition and dominance of western philosophy in the lives of Pacific people. It is about valuing alternative views about the world and emphasis on those rooted in indigenous cultures of the Pacific, and it is about creating a new philosophy that is culturally inclusive and gender sensitive.

Gegeo further pushes this decolonisation mission towards another level of 'dehegemonisation', so that the native Pacific Island scholars find their own research and epistemic frameworks rather than continuing to rely on the Western frameworks, this is to recognise how Pacific people communicate, think and learn. Understanding the ontological (the nature of what is being studied) and how to best understand this object or area of study (epistemology) is relevant to understanding differences in research approaches (Whitehead, 2004). The table below illustrates the ways of thinking between the Pacific and Western construct. 
Table 1: Ways of thinking between Pacific and Western

\begin{tabular}{|l|l|}
\hline Pacific Way & Western Way \\
\hline Communal & Individual \\
\hline Consensual & \\
(participation and shared decision making) & Confrontational \\
\hline Cooperative & Competitive \\
(positive outcomes for all) & (winners and losers) \\
\hline Reciprocal & Profit Seeking \\
(sharing and obligations to each other) & (only obligation is money) \\
\hline Spiritual & Secular \\
(sacredness) & \\
\hline
\end{tabular}

Source: Overton, 2010

Therefore through a Pacific epistemological lens the kakala research framework developed by Konai Helu-Thaman will be used to describe the research process for this research. A kakala is a garland of flowers in Tonga and it is used as a metaphor to describe the different steps in the research process. Thaman (1992) highlights the important skills required in the making of the kakala, selecting which flowers, which leaves, which people to gift it to and why. Like research there are skills required and the selection of materials are important in order to generate a final product that is appropriate and worthy to its audience. There are six stages in the kakala methodological framework (Thaman, 1992). 
Table 1 - Kakala Methodological Framework

\begin{tabular}{|l|l|}
\hline Teu & $\begin{array}{l}\text { Conceptualisation: perceptions, beliefs and } \\
\text { philosophies }\end{array}$ \\
\hline Toli & $\begin{array}{l}\text { Data collection methodologies (semi structured } \\
\text { interviews, talanoa) }\end{array}$ \\
\hline Tui & Analysis \\
\hline Luva & Reporting and outcomes \\
\hline Malie & Relevancy and worthwhileness \\
\hline Mafana & Application, transformation and sustainability \\
\hline
\end{tabular}

Source: Thaman, 1992

A Pacific perspective embraces culture and traditions, its way of thinking and modes of behaviour. It is essential for Pacific research to be culturally sensitive and appropriate. If the methodology is appropriate and engages in critical practice then the community being researched are transformed and empowered, thereby results will be useful and valued.

\subsection{Positionality and Reflexivity}

Positionality refers to aspects of identity in terms of race, class, gender, caste and any other attribute that are markers of positions within society (Chacko, 2004). When working in development with people and different positionalities, negotiating these changing identities is very challenging. Nonetheless, positionality is important when doing research whether it is researching a community you are familiar with or one that is foreign as it determines where the researcher stands in relation to the community or phenomena being researched. Positionality is a critical factor in framing social professional relationships. It sets the tone of the work affecting its 
course and its outcomes. The aspects of positionality matters because it influences these processes and outcomes. Acknowledging one's positionality would strengthen commitment to conduct good research based on building relations of mutual respect and recognition. It involves power relations and positions that are constantly negotiated (Sultana, 2007).

Ntseane and Muhamad (2001) state that positionality is a space where subjectivity and objectivity meets. It is understood that pure objectivity is very hard to achieve, and it would be naive to even think it is attainable (Bourke, 2014). We can aim to remain as objective as possible but our subjectivities will define our position, because you have to position yourself somewhere in order to say something (Hall, 1990).

Like many researchers there are many reasons in pursuing study of 'my own kind' (Kanuha, 2000); the population that I identify myself with and with whom I have historical and cultural ties with. When researchers are insiders, there is an established shared understanding and trust (Costley, 2010). To position as an insider or outsider researcher comes with its own complexities. It is difficult to clearly define the boundaries between an insider and outsider researcher. Breen (2007) states to take on the role as a researcher even if you are originally part of the group you are researching this already separates you. It brings out different dynamics of social differentiation that is beyond commonality in nationality or ethnicity (Sultana, 2007, p 374). Bonner and Tolhurst (2002) identified three key advantages of being an insider researcher: one having a greater understanding of the culture being studied; two, not altering the flow of social interaction unnaturally; and three having an 
established intimacy which promotes both the telling and the judging of truth. Furthermore, insider-researchers generally know the politics of the institution, not only the formal hierarchy but also how it "really works". They know how to best approach people. In general, they have a great deal of knowledge, which takes an outsider a long time to acquire (Smyth \& Holian, 2008). Therefore the advantages of being an insider researcher is possessing an understanding of the people, the community and culture before undertaking the study. It is valuable to have the ability to interact with the group naturally because of the level of familiarity (Kanuha, 2000). Having familiarity puts the researcher and the participants as co-researchers and colearners. This is important because it diminishes any power relations between the researcher and participants (Breen, 2007).

My positionality and personal experiences influenced the location of my research. I was born and raised in Niue. My parents attained tertiary level education, and this has rubbed off on my five siblings and I. Growing up in a large family my parents have always been huge advocates of education and culture. A focus on education is important because knowledge is power and this will open doors and takes us places and culture is critical because growing up in a small remote island we can fend for ourselves from the land and sea. We learn to appreciate the simple things in life and have a sense of belonging and independence. I was employed by the Government of Niue straight after secondary school for a number of years and this has enabled me to understand the structure, positions and systems of the local government. It positions me as an 'insider' with the officials in Niue I interviewed for this research. 
Before embarking on my field research I had a fair idea of my positionality and how I would be treated whilst doing my research. I was surprised that some of these aspects were reversed and that I had taken my positionality for granted. In some of my interviews I felt that I was categorised as an outsider, judging by the responses and deflection I received. I concluded that my status as a Victoria university student but not a Government of Niue (GON) employee may have influenced this viewpoint. Although negligible my age and position in government also added to this assumption. I was concerned that my familiarity will affect my rapport with respondents. It was beneficial in some instances because participants felt they could trust me and they were very open with their responses. It was also easier for flow of conversation because they did not see the need to explain certain details or background for their responses and arguments shared. I was able to fill in the gaps in the conversation. This is a luxury in my case compared to other development researchers who has this limitation (Murray and Overton, 2003). Other benefits or luxuries included the arrangement of meetings and interviews a lot quicker and with less hassle. The interviews and conversations were open and frank, and also went beyond their (respondents) positions to personal thoughts. There was also a downside to having open and frank conversations because in some cases it led to more gossiping and detracted from the element of professionalism in the research.

This familiarity and openness can also lead to diminished objectivity. Pitman (2002) argued that insider familiarity can lead to an 'illusion of sameness' and 
inside researchers tend to struggle to balance its role as an insider and as a researcher. Overall I was constantly reminding myself of my positionality.

Niue is a small place with a small population and there are concerns about anonymity. Identifying participants can have negative implications on them. Sensitivity to the respondents is also crucial and it is important to inform them as a matter of courtesy because the study is likely to affect their roles (Costley, 2010). Yet the research also provided the respondents a platform for voices that were often unheard, giving power to the respondents. But the biggest part of being an insider researcher is speaking the language and understanding the local values. I understood the cultural protocols knowing the formal and informal power structures of how to approach elders or those in respected positions. I was able to conduct the research in a short amount of time compared to an outsider researcher who would need to learn and familiarise with the place.

\subsection{Limitations}

Some limitations were also evident regarding my positionality and doing research as an insider possessing greater familiarity that sometimes leads to loss of objectivity. Limitations that have not been mentioned but are critical for research which includes researchers unconsciously making assumptions because of prior knowledge of place and community which is considered as bias (DeLyser, 2001; Hewitt-Taylor, 2002). Bias is always a limitation when doing research as an insider. The struggles surrounding role duality, balancing between an insider role and the researcher role can be confusing but to be aware of this is essential (Unluer, 2012; Gerrish, 1997). This is further 
supported by O'Leary (2004, p 46) when she talks about "how we make sense of the world through the rules we are given to interpret it. But because we are immersed in these rules and surrounded by them, they can be very hard to see". But understanding and recognising these helps researchers to avoid this trap of judging others realities in relation to their own. Being an insider with a close level of familiarity with the respondents, makes the respondents assume that the researcher know what they know or mean. Another challenge is being an insider with intimate knowledge of the study population (Kanuha, 2000) with a possibility to skew the outcomes. It is important in their interpretations to be aware to always check for clarification and explain their stance on the topic of discussion.

\subsection{Research Design}

The research examines the Paris Principles of aid effectiveness: in particular of alignment, ownership, harmonisation and mutual accountability. These are investigated at the country level and to see the extent it has been practiced in Niue. It will also consider how these principles of aid effectiveness have evolved over time.

The overarching methodology in this study is ethnography, defined as research that attempts to understand the reality of the researched (O'Leary, 2004, p129). The ethnographic approach that is used in the qualitative research design is a way of describing human behaviour, social life, and is centred on the study of different cultures of the group of people in their natural settings. The ethnographic research method means the representation of people in a cultural setting is often referred to as the interpretive, 
constructivist, naturalistic or post-positivist approach that answers the questions about the challenging and complex nature of what is being researched, with the aim of describing and understanding the phenomena from the respondent's perspective (Whitehead, 2002). According to Merriam (2001) on ethnographic approach in qualitative research used to identify patterns and relationships in their natural settings as well as attempting to understand and interpret these patterns and relationships from the perspective of the participants. It is important to do an ethnographic research to avoid any manipulation or alteration to my personal preference.

Ejimabo (2015) illustrates a qualitative research as a process that examines the patterns of meaning that emerged from the data collected. In qualitative study, people's words and actions represent the data of qualitative inquiry. The usefulness of undertaking qualitative research is that the researcher takes on the role as an active learner who can tell the story from the participants' view rather than an expert.

Ethnography is also an interpretive process. This is because all research findings are interpretations made by the researcher in the natural research setting. As such it is acknowledged that biased interpretations are possible based on culture, personal and theoretical paradigms brought to the research setting; as well as the dynamics in the research process and the interactions with the community. In an attempt to overcome this bias, methodological and reflexive methods are used (Altheide and Johnson, 1994). This is important because it concentrates on Niue government officials in their natural settings. It is associated with telling real life stories, an ethnographic approach based 
on the perspective of the participants. There will also be a case study of the NZAID programme in Niue. This hopes to collect insights and the potential it may have in influencing policy, practice and future research (Merriam, 2001). In order to overcome my biasness I've used reflexivity to enhance my interpretive validity. Reflexivity is reflecting on how the researcher is observed as part of the research setting that includes power relations, context, culture and how that influences interpretations, methods, and knowledge (Sultana, 2007).

\subsubsection{Qualitative Approach}

The aim of this research is to evaluate aid effectiveness in Niue development policy and practice. Emphasis is not on the funds received from aid, rather this study seeks to answer how government officials explore, interpret and make sense of the social world (Bryman, 2004). There are three main reasons which differentiate qualitative research from other methods. Firstly, data is collected in natural settings rather than collection in laboratories. Secondly, instead of testing theories qualitative research generates theories and lastly it looks at how people live the way they live (Bryman \& Burgess, 1999).

All researchers begin data collection with assumptions about their research topic, and the people they plan to interview. One of the main purposes of doing field research is to 'sensitise the researcher to the parameters and nature of the community' (Field, 1991, p91). The benefit of this is the researcher can observe what happens in the natural setting. It sets the researcher as the instrument of data collection (Bourke, 2014). Problems will arise if researchers enter the study with the mind-set that culture is already familiar 
because the researcher may overlook or miss some important pieces of data (Field, 1991). Qualitative research is beneficial because it provides an understanding of the situation through the experiences of the people. Therefore this research is largely qualitative and the use of semi-structured interviews as the main form of data collection.

\subsubsection{Talanoa Research}

Largely in the Pacific Islands traditional knowledge and customs are passed through story telling from one generation to another. This research will use the 'talanoa' method as a means of collecting data. Talanoa is a communication tool of story-telling, debating, reflecting and sharing (Vaioleti, 2006). Talanoa is chosen for this research because it relates to how Pacific people act, live, perform in everyday life. It aligns with the Pacific way of thinking, acting, the language and culture and its associated rules and protocols. This sense of appropriateness captures the authentic experience of what is researched (Vaioleti, 2006).

Traditional protocols are important in the Pacific culture therefore if protocols are ignored and not respected then the talanoa can end and research results will be unreliable or not gathered at all (Otsuka, 2005). However talanoa can produce some deep discussions and build strong relationships. Strong relationships are important in creating trust and fostering that trust. Although talanoa is imbedded in the Pacific way of life it also has its limitations. Talanoa in its other forms are gossiping and joking; therefore can lead to inaccuracies of information being provided or lose the element of professionalism. Otsuka (2005) reminds us of the importance of data 
triangulation, this is to validate information that has been shared. Validation can be done through the interviews with the respondents.

\subsubsection{Interviews with Government Officials}

I made contact with potential interviewees in March 2016. I commenced my fieldwork in July 2016 and I was in Niue for three weeks. The three weeks in the field was spent interviewing respondents and gathering relevant statistical data and reports. The government officials that were interviewed were mid to senior officials that are actively working in development policy and projects in Niue. Some of the interviews conducted were interrupted as participants needed to attend to other of their pressing responsibilities that came up during the interviews. One interview had to be rescheduled several times because the respondent needed to be at another meeting with a development donor discussing a potential million dollar project for Niue. Three interviews did not happen because officials needed to address other issues that came up during the scheduled meeting time.

Semi structured interviews were conducted with 12 current government officials. Reports were also used as part of the analysis. The interview questions (Appendix one) was used as guidance during the conversations with participants, however the interviews were in a talanoa approach letting the participant talk freely and openly. The talanoa was more conversational because this provides a space that is comfortable for the participant. A 30 minute timeframe was suggested at the outset of the interview but participants were not restricted to this if they were comfortable with longer. 


\subsection{Ethical Considerations}

The human ethics policy of the University of Victoria is tasked with the core purpose of maintaining ethical standards when dealing with human participants. Ethical research has been criticised as an institutional paper work, a tick the box activity to make superiors happy. An aspect that should be looked into ethical research is how to bridge the differences of Pacific and Western knowledge. This is suitable for Pacific because there are differences in how knowledge are understood and performed from a traditional and cultural aspect and a Western and formal ethical codes. For example, as part of the human ethics protocol of Victoria University it requires signed consent from all participants and this was completed before all interviews commenced. Participants were by and large happy and willing to talk freely, but I noted a difference when asked if the interview could be recorded. I noticed a change in the respondent's body language and there was a noticeable pause before anything was said thereafter. As a result three interviews, were not recorded but permissions were still received to be interviewed. I feel that utilising a Western idea on a Pacific context further perpetuated this notion of 'othering' between me and the respondents. The term othering in its simplest form is a process where the boundaries of understanding and interacting with those observed as different (Canales, 2000). I was aware and conscious of the difference between the respondents when interviews were rushed, and others with guarded responses.

Every interview I was constantly negotiating my positionality in order to build a positive rapport with the respondents whilst still mindful of ethical codes. Sultana (2007) raised a very good point about good ethical guidelines of 
institutional paperwork that is not usually captured but negotiated on a daily basis in the field, such as how I spoke, how I dressed, where I sat in an interview, and how I addressed different people. Certain aspects are easy to employ because of my Niuean cultural upbringing, like how to behave in front of elders, what to say to elders and when to say it, as well as respectable dress code. These are all part of Pacific culture and protocols.

The most critical ethical consideration is confidentiality of the participants. This is important because I do not want any of the responses to rebound on the respondents. The last thing I want is for participants to receive negative consequences from the research study. Therefore maintaining confidentiality is vital. Ethical standards are always evolving with time, but it is our responsibility to ensure that participants are respected and protected.

\subsection{Summary}

This chapter has outlined the methodology and methods used in collecting data for the research. The chapter has identified the Pacific epistemological approach and the importance of this. It is very important to recognise and use culturally appropriate research methodology with Pacific people. I have also identified the benefits and challenges being a researcher researching my own kind. I believe whether insider or outsider researcher both carries advantages and disadvantages the only differences will depend on the researcher and how s/he understands the circumstances and purposes of the research. Ethical considerations must also be taken into account to avoid displacement of the research of those being researched, and the researcher. 


\section{CHAPTER 3: NIUE AND ITS RELATIONSHIP WITH NEW ZEALAND}

\subsection{Introduction}

This chapter will introduce Niue, its decolonisation and development journey. This chapter will also present New Zealand and its history with Niue, its development policies and aid delivery regimes. New Zealand and its development assistance to Niue is explored for two reasons, because of the Constitutional arrangements, and to see how the policies have influenced Niue's development. The review of Niue and New Zealand's development efforts could assist Niue streamline its processes and coordinate its aid agenda. A peer review of Niue's development efforts was conducted in May 2011 by a committee from the Pacific Islands Forum Secretariat, and this took stock of the Governments activities involving strategic planning, financial management, transparency and accountability. It was an opportunity for the government to see if the path it was taking was the correct one and to consider suggestions for improvement.

\subsection{Context}

Niue consists of a raised coral atoll, approximately $480 \mathrm{~km}$ east of Tonga and $660 \mathrm{~km}$ southeast of Samoa. It is approximately $2,400 \mathrm{~km}$ northeast of New Zealand. Niue's coastline is rugged and rocky, with 14 villages spread around the island. Each village has its council with elected representatives. Niueans are New Zealand citizens which enables Niueans to migrate freely, which many have done. The census in 2011 recorded a population of 1,611. The population reached a peak at just over 5,000 in 1966 but has since steadily 
declined (GON, 2016). The majority of Niueans view New Zealand as the land of milk and honey which has made the move for many Niueans to New Zealand even swifter. The shift overseas is attributed to employment opportunities and education. The Government of Niue is the major employer, and the backbone of Niue is its Public Service. Some of the concerns that make Niue's economy vulnerable are low population, scarcity of natural resources, and its isolation and high costs of transportation. The Government of Niue is committed to building the population and diversifying and increasing its revenue base (GON, 2016) and I believe investigating the aid effectiveness agenda in Niue's development strategies is vital for this to occur; evidently, there is a consensus that aid does promote growth and reduce poverty (Hudson, 2004; McGillivray 2004; Clemens, et al. 2004).

Niue is ecologically fragile. This fragility became apparent in January 2004 when it was hit by tropical cyclone Heta with winds of approximately $275 \mathrm{~km}$ per hour with associated destructive wave surges. It destroyed the land and infrastructure of the capital, literally sweeping the land into the sea and completely destroyed the only newly refurbished hospital. This event alone resulted in an obvious spike of residents migrating overseas. Those that remained on Niue were determined to rebuild what was left which was laden with hardship and expense.

\subsubsection{Colonisation and decolonisation}

Niue was discovered by Captain Cook in 1774. Between 1846 and 1901 it was dominated by the London Missionary Society (LMS) which undoubtedly 
was the motivating factor that pushed the Niue people towards British sovereignty. Niue made three petitions for British protection, the first appeal was made in 1887 and two other petitions followed in 1898 and 1899 (Chapman, 1976). Niue only became a British protectorate in April 1900, and was included within New Zealand's boundaries in June 1901 (Chapman, 1976). This transfer of colonial power was described by Scott (1993) as 'Niue was scrap from the British lion's feast of empire to the smallest cub' (Scott, 1993, p 17).

New Zealand's colonial regard in Niue was at best mixed. Administrations were sometimes incompetent, insensitive and unjust (Scott, 1993). New Zealand's first four decades on Niue involved very little change (GON, 1982). The first positive sign of New Zealand's genuine concern for the welfare of the people of Niue came in 1943 with the establishment of the Department of Island Territories then in the 1960's New Zealand's subsidies (aid then) to Niue rose so high it became disproportionate with Niue's ability to raise local revenue (Chapman, 1976).

The first step towards modernisation in Niue came in 1944 when the New Zealand Director of Education commissioned an in-depth study of Niue's education needs as well as in December 1962 where Niue expressed its desire to the United Nations (UN) for self-government (Chapman, 1976). A lot happened in the ten years that followed Niue's request to the UN, which included a re-constituting of the Niue Executive Committee as a Cabinet in 
1964, the closing of Resident Commissioners as Head of States in the Niue Executive Committee in 1968, to Niue's first Public Expenditure Committee in 1969 (Chapman, 1976).

It was only in 1974 that Niue fully progressed with the new Constitution confirmed in a referendum giving the people of Niue the freedom to control its own government $(\mathrm{GON}, 1982)$. The leaders of Niue at the time were instrumental in negotiating an arrangement that was advantageous and beneficial for the people of Niue then and now. The arrangement enabled Niue to take control of its own destiny (for example make its own laws) while still maintaining a constitutional relationship with New Zealand. Niue became a self-governing country in free association with New Zealand. The uniqueness of this arrangement and Niue's self-governing entity is captured in this quote by Professor Tony Angelo of Victoria University; “To look after one's own affairs or to be free to control oneself are enduring aspects of the human condition. Aspiring to this seems natural. Children grow up and leave home. They wish to be free to make their own way and have the benefits and the responsibilities of their actions. And so it is with countries. They too wish to have the freedom to govern themselves and to be able to take individual pride in their achievements" (Angelo, 2004, p 329).

\subsubsection{A Realm Nation}

The Realm of New Zealand is an ambiguous concept. The Realm comprises of five components and these are the State of New Zealand, the self-governing State of Niue, the self-governing state of Cook Islands, the Ross Dependency and Tokelau (Quentin-Baxter, 1983). The Realm identifies Elizabeth II as 
Head of State, and the State of New Zealand is understood as the second most important element. It is the State of New Zealand that provides the main link for the other four components in the Realm. The following six features sits at the core of the free association relationship of Niue and New Zealand:

1. Shared Head of State

2. Self-Government

3. Common Citizenship

4. Economic and Administrative Assistance

5. Defence and Foreign Affairs

6. Cooperation, Constitution, and a Commitment to Shared Values

The people of Niue, Cook Islands and Tokelau are New Zealand citizens by birth in their respective island nations. An aspect with New Zealand's privileged position within the Realm is the appointment of the Governor General which was previously filled by British aristocrats until 1967 (Townend, 2003). The appointment of the Governor General is by the Queen on recommendation of the New Zealand Government. Niue is only advised of the appointment of a Governor General but has no say in it, even though the role of Governor General is formally as much as Niue as it is New Zealand's. The former Niue High Commissioner Takelesi in 2002, says "Niue is happy with these lopsided arrangements, as long as the appointees are competent in Niue affairs and the office is maintained at New Zealand's expense" (Townend, 2003). 
Niueans place a high value on its New Zealand citizenship because it is perceived by Niueans as an insurance reference for social, economic and possibly political matters. Niue acknowledges this privilege and entitlement because of its automatic New Zealand citizenship status. However, this privilege may have brought about complacency. Complacency in a sense that Niueans don't question their privilege, their right as a New Zealand citizen, because Niueans believe that they are in itself already privileged having automatic access to New Zealand compared to other Pacific islands.

The economic and administrative assistance from New Zealand to Niue is not clearly defined. The Niue Constitution Act 1974 section 7 states that "it shall be a continuing responsibility of the Government of New Zealand to provide necessary economic and administrative assistance to Niue". This resolution was accepted by New Zealand Government, upon this constitutional arrangements were enacted by the New Zealand Parliament and the New Zealand Government's assurance of continuing economic and administrative assistance to Niue was given statutory form (Quentin-Baxter 2008). The uncertainty is positioned on how the 'necessary' is defined. Quentin-Baxter (2008) in her article specifies that the amount of money provided "must enable the people of the associated State to enjoy a standard of living that is reasonably comparable with the standard of living in New Zealand". A report by the Ministry of Foreign Affairs and Trade (MFAT) in New Zealand claims a need for a new approach regarding New Zealand citizen overseas who receive lower standards of basic services than New Zealanders living in New 
Zealand (MFAT, 2010). Hence being a New Zealand citizen outside of New Zealand is different to being a citizen in New Zealand.

\subsubsection{Strategic Development}

The vision for Niue's national strategic plan in 2009 - 2013 is for a 'Prosperous Niue - Niue ke Monuina'. The objective of the plan was to build a sustainable future that meets the economic and social needs while preserving environment integrity, social stability and the Niue culture. The strategic plan comprises of five pillars: financial stability, governance, economic development, infrastructure, social and environment. The plan was seen as a framework that provides directions for Niue to follow and enable the nation to achieve prosperity for all. The priority sector for economic development and continued sustainability for Niue is tourism.

New Zealand jointly identified tourism as Niue's best opportunity, and the goal was to develop a full tourism package to promote Niue as a unique and pristine tourism destination. This began with developing new accommodation in Niue. Tourism alone was not enough to create economic sustainability hence Niue's discussions on renting parts of its exclusive economic zone (EEZ) that never really transpired.

The damage on crops caused by droughts stopped growers exporting taro to New Zealand, and tropical cyclones like Heta in January 2004 is a constant reminder of the effects nature has on the development of Niue. These natural disasters alone destroy crops for export as well as damage infrastructure further decelerating development in Niue. 
The Government of Niue entered into two substantial ventures that was anticipated with a potential to significantly boost Niue's economy. One was opening a fish processing plant in Niue in 2004 with Reef Group to export fish to Japan, USA and New Zealand. Unfortunately it did not live up to its expectation and was halted due to low catch rate (SPC, 2009). The second venture was also with Reef Group and consisted of a large-scale nonu (Morinda citrifolia) plantation and nonu juice processing facility (GON, 2004). The aim of the venture was to export organically certified nonu juice to similar markets as the fish. The nonu facility still operates today but it has also not lived up to the hype initially expected.

Niue's only power station in 2006 went up in flames destroying its generators and leaving only two operating for the whole island. This caused electrical disruptions and power blackouts for the island. These are just a few examples of the type of impediments Niue encounters in its development pursuit.

Niue has experienced continuous population decline because of the free association relationship with New Zealand which allows Niueans to freely move to New Zealand. This have had a negative impact for Niue because the island continues to lose its able and skilled human resources. In the early 1990's there was pressure from the New Zealand government on Niue to reduce its public service which resulted with many skilled and qualified public officials and their families migrating overseas. In 2007 all public servants were obliged to take a 10 per cent pay cut for three months due to severe government budget constraints (GON, 2004). Although this was adjusted back to normal later, its effects created doubt for Niueans in the 
ability of the government to achieve what was reflected in the Niue Integrated Strategic Plan from $2003-2008$.

Niue has invested in many big projects but the shortage of skilled workers is a constant issue causing Niue to recruit from overseas. For example, Filipino teachers are employed at Niue High School, and Kiwi carpenters are recruited for construction and extension of the Matavai Resort. It is a constant challenge for Niue to create an economic environment for its citizens and also employment and investment opportunities to attract Niueans abroad.

\subsubsection{Economy and aid}

Budgeting and financial systems for the government is regulated by the Constitution of Niue and the Niue Public Revenue Act 1959 (Niue Constitution, 1974). The operational plans of all government departments make up the national budget. The national budget consists of outputs and outcomes and what funds were used for. Most of the government funds are spent on salaries and essential utilities such as power and water (PIFS, 2011). Niue's economy in the past 40 years has been heavily reliant on budgetary support from New Zealand. New Zealand provides almost $50 \%$ of the GDP through budget support programmes (PACC, 2007). The economy has undergone considerable structural change since the early 1990s, with the downsizing of the public sector by more than $50 \%$ and corporatisation of certain government activities (PACC, 2007). The economy now is stable and it is dominated by the public sector accounting for approximately two thirds of employment (PIFS, 2011). 
The government does not have a very large revenue base but other sources of financial resources included taxation, government trading activities, sovereign assets and additional support from development partners (GON, 2016). Niue is an upper-middle income country, with a gross domestic product (GDP) of NZD\$24.7m in 2014, or \$15,205 per-capita terms at 2009 prices (GON, 2016). New Zealand is Niue's major trading partner, however, there is a large trade imbalance with imports of approximately $95 \%$ from New Zealand compared with exports (GON, 2016). There is a total of NZD\$15.1 million in exports to Niue and approximately NZD\$400,000 in imports (MFAT, 2016).

The MIRAB model by Betram and Watters was developed to describe the colonial links between New Zealand and the island states. The MIRAB model was based on the elements of migration, remittances, aid and bureaucracy (Betram and Watters, 1985). The model was concerned with the integration of island economies with New Zealand and how this process could turn the island from resources-based into rent-based economies (Betram and Watters, 1986, p 57). Interesting from the MIRAB model is the idea of "transnational corporations of kin" meaning migration from islands were shaped by the collective decision of family units instead of an individual decision, because this was regarded as profitable for the wider family. The idea of transnational corporations of kin was argued as a "fallacy of misplaced familism" by Hayes (1991, p 43). Nonetheless, an advantage of the MIRAB model is that it challenged the aid donor's motives for small island economies to move away from its natural pattern of development and into a development model 
transferred from elsewhere (Bertram, 1999). These motives included pouring large sums of monies into island economies in an attempt to trigger exportled growth seen in economies in Asia.

Inflows of overseas development assistance (ODA) underpin Niue's good macroeconomic performance. ODA received by Niue ranged between USD\$14-\$21 million during the past five years (GON, 2016). Aid to Niue is directed through general budget support, program support for asset management, technical assistance and contributions to the Niue International Trust Fund (PIFS, 2011). Aid management functions and systems are not well established in Niue. Niue's suffers from the typical Pacific island problems of geographic isolation, few resources, and a small population.

\section{Graph 1 - Niue Official Development Aid (\$US million)}

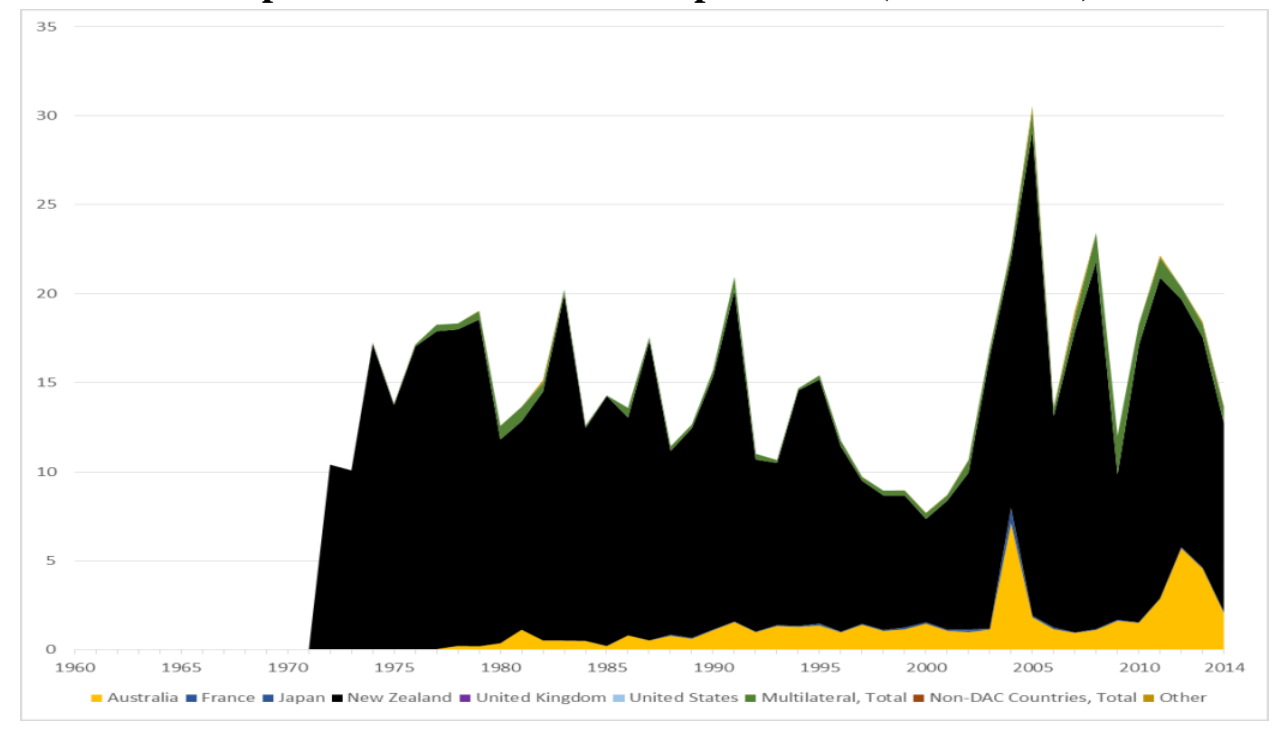

Source: www.oecd.org 
A trend in Niue's development aid (graph 1) will be deduced using the conventional development theories and this will try to determine if the Niue's development journey has been influenced by global trends and agendas.

Decolonisation and modernisation 1960 - 1980: These were exciting times for Niue. Niue successfully won its bid for self-government and not long after New Zealand's Resident Commissioners as Head of States in the Niue Executive Committee ended. There were new hurricane houses around villages, deep-water bores were first drilled around the island. Two UN agencies funded a water reticulation scheme to supply water to the villages. Motor vehicles especially bikes were imported. Movies were now shown in most villages, a local newspaper was established as well as a radio station. During this time more than 30 Niuean students were on scholarships in New Zealand and agricultural training around the Pacific. But the biggest financial undertaking was the construction of Niue's airport which first started operating in the 1970 s.

Developmentalism 1980 - 1990: the vibrancy and prosperity in the last two decades continued into the 1980s for Niue. The growth in modernisation became a double edge sword for Niue, with Niueans migrating to New Zealand. Some have suggested that this was a result of the airport. However the migration had already begun much earlier the airport just became a faster route. The government of Niue at this time underwent changes which included a $10 \%$ salary reduction from all public servants to cater for government deficits. 
Neoliberalism 1990 - 2000: Neoliberalism is basically the rolling back of the state and giving power to the markets to regulate. There were further changes for the Niue government with huge cuts in the public sector further pushing migration of Niueans to New Zealand. There were only slight increases in export statistics but not impressive to continue. From 1996 to 2005 Niue's export to New Zealand totalled $\$ 316,536$. This dropped by $43 \%$ a year later to $\$ 179,347$. It further dropped in 1998 to $\$ 104,493$. The downward trend was reversed in 1990. This is a remarkable turnaround of $165 \%$, and peaked in year 2000 at $\$ 643,041$ (Niue Statistics, 2005).

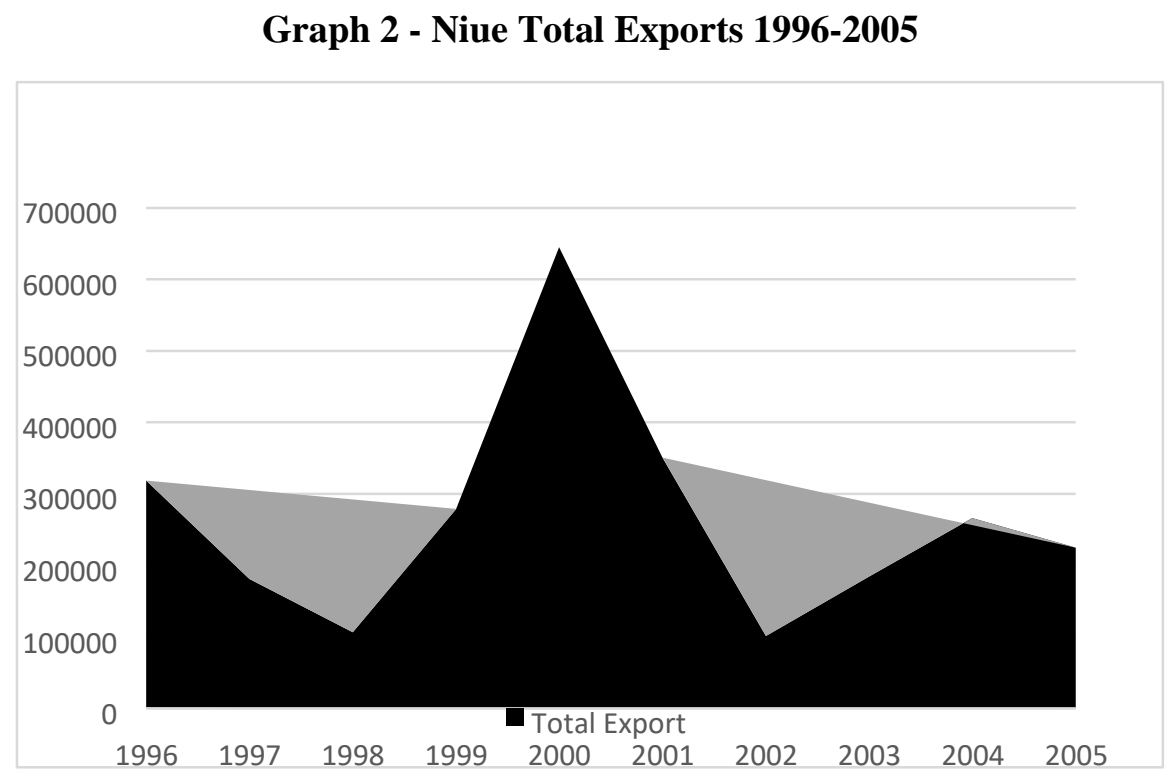

Neostructuralism 2000 - 2010: Neostructuralism is reinstating a balance to the relationship between society and the government which was brainwashed by neoliberalism (Murray \& Overton, 2011, p 311). The neostructuralism era was dominated by the Millennium Development Goals (MDGs) which saw 
development donors giving aid for poverty alleviation, security and state building purposes. For Niue the pattern for exports from 2000 onwards seesawed (Niue Statistics, 2005). On the other hand this period recorded the highest ever aid received by Niue. The highest in 2004 was attributed to rebuilding efforts caused by cyclone Heta.

Retroliberalism 2010 - current: This is a fairly new and unknown concept, but retroliberalism is the term used to describe how the global aid regime has performed after the Global Financial Crisis (GFC) (Murray and Overton, 2016). Interestingly Niue's current development efforts mirror the aspects of a retroliberal approach. Some of these include the key idea that economic growth is the target of New Zealand development aid in order for Niue to achieve self-sufficiency, and evidently this is done through the promotion of the private sector. Niue on its part listed private sector as one of the core pillars in its national strategic plan from 2009 to 2013.

\subsubsection{Transformation of Public Sector}

The government proposed changes in the public sector with the aim to improve the delivery of services provided by the public sector that will lead to improved prosperity of Niue. The guiding principles for the transformation are exactly the same principles in the Niue National Strategic Plan 2009-2013. The Government had over 15 different departments and these were amalgamated into five super ministries which are central services, social services, natural resources, infrastructure and commercial and trading arm. 
The five main categories in the transformation and their intended roles are illustrated in the table below with the pillars in the NNSP that the categories align to.

Table 2 - New Government Ministries and Associated Development Pillars

\begin{tabular}{|c|c|c|}
\hline Central Agencies & $\begin{array}{l}\text { Responsible to the executive } \\
\text { branch in the discharge of their } \\
\text { functions and for policy support } \\
\text { to all of government }\end{array}$ & NNSP Pillar: 1,2 \\
\hline Social Services & $\begin{array}{l}\text { Provide community and social } \\
\text { services }\end{array}$ & NNSP Pillar: 4,6 \\
\hline Natural Resources & $\begin{array}{l}\text { Deal with natural resources with } \\
\text { the primary role of conservation } \\
\text { and sustainable development }\end{array}$ & NNSP Pillar: 3,5 \\
\hline Infrastructure & $\begin{array}{l}\text { Pure service providers for the } \\
\text { basic structures of the island }\end{array}$ & NNSP Pillar: 3 \\
\hline $\begin{array}{l}\text { Commercial and } \\
\text { Trading }\end{array}$ & $\begin{array}{l}\text { The main aim to earn more } \\
\text { revenue to support government } \\
\text { policies to: Reduce losses and } \\
\text { lessen reliance on external } \\
\text { sources Have more efficient use } \\
\text { of resources }\end{array}$ & NNSP Pillar: 1,3 \\
\hline
\end{tabular}

Source: GON, 2016 
The transformation has taken a while to eventuate but it has accelerated and become even more rapid in recent years. The economy as mentioned in previously has shifted from public service to private sector and even within the public service the dynamics has changed. The functions and services for different departments have changed. The salary dynamics was a big component of the transformation having changed to a more performance based type and defining the set of criteria to encourage increased productivity. The cries of officials was to increase salaries to be closer to New Zealand levels. An unusual but exciting feature of the transformation was the fourday week which started in 2014 and is still in operation now. Essentially the four-day week stipulates that workers will take Fridays off and still be paid. This came about because the government promised public servants a 20 per cent increase in wages but an alternative of a four-day week was actioned. The scheme have had a lot of criticism with an opposition member of parliament calling it a 'Mickey Mouse' (RNZI, 2014). Funding of the transformation was a concern, however the Niue Philatelic and Numismatic, Bond store, taxes and others were believed to have sourced the transformation.

\subsection{New Zealand Aid}

\subsubsection{History}

New Zealand has participated in aid since the 1960s. Although virtually she ignored her territories for many years prior to this, her policies were altruistically intended (Chapman, 1976). Prior to the Second World War the amount that New Zealand contributed to Niue was insignificant. In the early 1950s, subsidies (what aid was called then) to Niue had dramatically 
increased and it was no surprise that the Larsen affair prompted New Zealand in the need to pay more attention to Niue (Chapman, 1976, p 10).

In October 1974 affairs relating to Niue was the responsibility of the Department of Island Territories of the New Zealand government but the department ceased not long after and responsibilities was relocated to the Ministry of Foreign Affairs and Trade (MFAT) (Quentin-Baxter, 2008). The transfer of responsibility from the Department of Island Territories to MFAT brought with it a different culture. A year after this change it was decided after little or no consultation with the Government of Niue that New Zealand's economic assistance to Niue were to be administered in the same way as its aid to all other recipients as part of the New Zealand ODA programme. MFAT had merged the financial assistance of the self-governing States of the Cook Islands and Niue to the Ministry's official development assistance budget. Before this change occurred it had its own separate appropriation budget of the financial assistance. It seemed the inclusion of payments to Niue in the budget appropriated for the NZODA programme was essential for New Zealand to meet the recommended proportion of Overseas Development Aid to Gross National Product in accordance with its obligations as a member of the OECD. Since the financial support to the Government of Niue was channelled through NZAID, there was a tendency to lose sight of its true character (Quentin-Baxter, 2008). The Ministerial Review Team that reviewed New Zealand's ODA programme in 2001 recommended that direct financial support to Niue should not be met through ODA (Ministerial Review Team, 2001). 


\subsubsection{Development Policy}

Currently the Pacific accounts for $60 \%$ of New Zealand's bilateral aid (Hayes, 2010, p 52). The New Zealand aid programme has continued to expand from the time it first began to provide foreign aid to its colonial dependencies in the Pacific in the 1920s. ODA in the 1970s focused on two main concerns, a commitment to the South Pacific and its involvement in South-East Asia (Banks et al, 2012). Aid at the time was used as a tool for New Zealand's foreign policy, where it was given mainly for political purposes instead of humanitarian (NZODA Annual Review, 1991-92). The Pacific has always been at the forefront of New Zealand's foreign policy (Thakur, 1991).

The Kirk Labour government in $1975 / 76$ saw a strong commitment to the Pacific, aid volumes were considerably high recording an equivalent of $0.5 \%$ of GNP in 1976 (Scheyvens and Overton, 1995). The Lange Labour government in the mid to late 1980s was focused on neoliberal reforms, with very little change to the aid budget. Aid volumes dropped to less than the 1976 levels, around $0.25 \%$ of GNP (Banks et al, 2012). The aid budget for the Bolger National government in 1990 was also low and very stringent compared to the Lange government. A noticeable difference was New Zealand economic motives which influenced where its ODA was directed. This was noticeable in the new aid relationships established with China, Cambodia, Laos and Vietnam. It was evident that the key feature of the aid programme in the 1990s were commercially focused and it was interesting that MFAT was making strong statements that the main objective of the New Zealand aid programme was poverty alleviation which was later dropped and 
replaced with sustainable development (Banks et al, 2012). In 2002 NZAID became a separate organisation from MFAT until the National-led government elected in 2008 redirected NZAID back into the MFAT. The National-led government in New Zealand in 2009 was a significant change in the direction of the aid program to Niue, highlighting economic growth as its focus.

\subsubsection{Aid Delivery}

In 2014, New Zealand's total ODA increased both in total dollars and as a percentage of GNI. Currently NZAID provides over NZD\$605 million in its aid programme and $60 \%$ of this goes to the Pacific (MFAT, 2016).

Figure 1 _ Country Aid from New Zealand

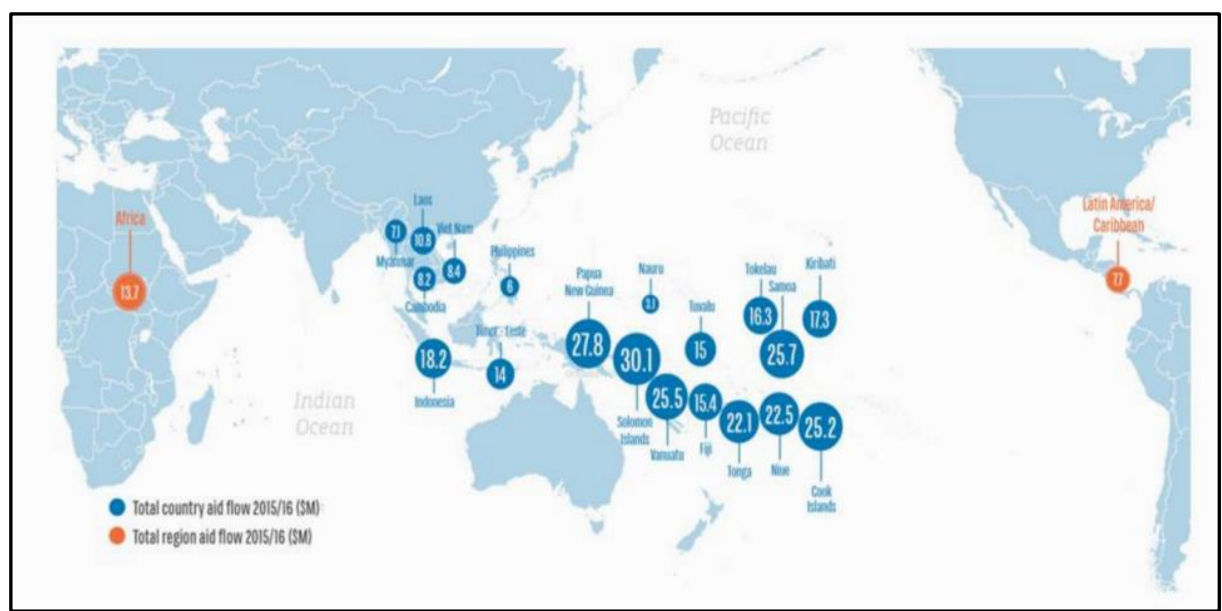

Figure 2 - New Zealand's ODA and ODA/GNI 2011-2014

\begin{tabular}{lllll} 
& $\mathbf{2 0 1 1}$ & $\mathbf{2 0 1 2}$ & $\mathbf{2 0 1 3}$ & $\mathbf{2 0 1 4}$ \\
\hline NZ ODA \$m & 537.14 & 554.60 & 558.06 & 605.65 \\
ODA-GNI \% & 0.28 & 0.28 & 0.26 & 0.27
\end{tabular}

Source: MFAT, 2012 
New Zealand aid is critical for the development of Niue, but its delivery mechanisms have been a concern (Liuvaie, 2009). These concerns are around its 'excessive bureaucracy, heavy handedness approach and bullyboy tactics', factors that goes against the principles for effective aid (Liuvaie, 2009).

\subsection{Summary}

Niue has undergone significant developments. It is fascinating to see the Niue's journey and compare events with the global currents. The government of Niue and its people have benefitted tremendously from development aid from various development donors but especially from New Zealand. Some have said that the history between Niue and New Zealand has borne inadequate outcomes. And there are serious concerns around Niue's economic and constitutional viability because of the population continues to decline. Looking towards the future it is uncertain if Niue would reach selfsufficiency and it may well continue to depend on New Zealand. Aid allocation from New Zealand to Niue is shaped by global trends in aid but also due to the frequency of natural disasters and their severity. Niue is yet to fully understand the scope of being part of the Realm which may have implications on its development. 


\section{CHAPTER 4: GLOBAL AND REGIONAL DEVELOPMENT POLICY PARADIGM}

\subsection{Introduction}

This chapter examines the regional and global aid agenda. It will identify the global agreements that were endorsed at four high level forums and agreements for the Pacific region in pursuit for aid effectiveness. It is important to see what is happening at the global scale so we can see the best way forward by understanding the concepts; and identifying what can be utilised for the benefit of the Pacific. But most importantly see how these global trends affect the Pacific Islands. With the multiplicity of development donors doing business and the growing interest of those wanting to do business in the Pacific, many agreements were endorsed by Pacific Leaders to protect, reap, as well as coordinate and harness efforts for best results. The Pacific island countries (PICs) have their own unique challenges and finding what is right for each is not easy. Niue draws strength from its neighbouring islands, drawing on the aid best practices from islands and its plans and mechanisms for development cooperation.

\subsection{Aid Thinking and Development Policy}

Modernisation dominated the aid agenda from the 1950s to the 1980s. Modernisation is a transition from a traditional society to a modern society. It is perceived to be a positive type of development which have led to the development in the fields of technology, education and markets to name a few. Because of man's natural drive to constantly improve. Walt Rostow (1957) identified two specific roles for aid in order to achieve faster rates of 
economic growth; the first was technical assistance (in terms of external specialists) and the second was financial capital. But like anything it had consequences, modernisation saw little value in 'traditional' society or economy. These were to be replaced by modern forms, it was led by the state not the market.

Neoliberalism dominated the development discourse from the 1980's to the early 2000s. The fundamental elements of neoliberalism is free market allocation, simply putting the market at the forefront of development strategies in order to stimulate exports and the private sector. During this time the role of governments were side-lined and structural adjustment programmes (SAPs) were promoted. SAPs were sought to dismantle state controlled institutions and regulations. Things like government's services and costs were cut, import and export controls were abolished and restrictions on markets and trade were deregulated (Murray \& Overton, 2011). It was assumed that economic growth through neoliberalism will eventually filter down to the poor. However, this neoliberal reform only created new forms of poverty and inequality. Seeing that only the elites were benefitting from this neoliberal position, governments intervened.

The 2000 to 2010 period was dominated by the principles of neostructuralism. Neostructuralism was a shift from the market neoliberal approach and giving control to the government. The idea was to restore balance between society and the state, which has been attacked by neoliberalism (Murray \& Pastor, 2008). Neostructuralism is seen as a middle road to globalisation, without the heavy rules of neoliberalism. It focuses more on participation, social inclusion 
and growth with equity (Brohman, 1996). The rise of neostructuralism was a post neoliberal paradigm; however some have argued it was simply neoliberalism dressed up in a more acceptable manner.

The Paris Declaration (2005) and the Millennium Development Goals (MDGs) marks the neostructural turn recognising the importance of the state as the key agency for development rather than the focus on the idea of the market. The first principle of the Paris Declaration namely ownership was understood as the most important. It recognises and acknowledges that national governments having ownership of their own development strategies will achieve their development goals. Although aid is often perceived as charity, in reality it is more about the political and economic self-interest of the giver with much of it usually being tied aid. Tied aid where the donor country prefers the procurement of goods and services to be sourced from the donor country itself.

One would think that who you give your money to and how you give your money would be easy. Yet we all know the who and how is now more complicated than we first believed. There is more to aid than just handing over a cheque, there are now rules and terms of conditions that makes giving money away hard.

\subsubsection{What, Who, Whom and Why Aid}

Aid can mean many things to different people, but the charting between those that give aid and those that receive aid never changes. What counts as aid and what is not has been led by the Development Assistance Committee (DAC) of the Organisation for Economic Cooperation and Development (OECD). 
This committee was established in 1960 to coordinate and promote aid from donor governments and it has taken over ten years since the establishment of the committee to simply agree on a definition of aid. Foreign aid is not without controversy, and the controversy is around the volume and the impact of the aid on the development of the recipient country. Aid in its broadest definition refers to all resources - from physical goods, skills and money (either loans or grants) transferred by donors to recipients. But even this does not fully identify who the donors are and who the recipients are and why has there been a transfer of resources from one to another. Therefore, DAC defines ODA as "those flows to countries and territories which are provided by official agencies, including state and local governments, or by their executive agencies; and each transaction of which:

a) is administered with the promotion of the economic development and welfare of developing countries as its main objective; and

b) is concessional in character and conveys a grant element of at least 25 per cent (calculated at a rate of discount of 10 per cent)."

Aid critics have said that aid has been ineffective and at times have made matters worse. Those who advocate for foreign aid have argued that aid has been effective in establishing reforms and global agreements (Alesina \& Dollar, 2000). One of the challenges of assessing the effectiveness of aid is that not all aid is intended to generate economic growth. Some of the aid is for humanitarian purposes, helping people improve their standard of living (Barder, 2009). 
Table 3 - Differences in Conceptions of Power between Development Partners and Governments

\begin{tabular}{|l|l|l|l|}
\hline partners & Partnership & Harmonisation & Understanding \\
\hline Development & $\begin{array}{l}\text { Power is } \\
\text { constructive } \\
\text { (Power to) }\end{array}$ & $\begin{array}{l}\text { Power is used to } \\
\text { prioritise some } \\
\text { issues over others }\end{array}$ & $\begin{array}{l}\text { Power stems from } \\
\text { formal institutions }\end{array}$ \\
\hline $\begin{array}{l}\text { Partner } \\
\text { governments }\end{array}$ & Power is & $\begin{array}{l}\text { Power is seen as } \\
\text { limiting national } \\
\text { initiatives }\end{array}$ & $\begin{array}{l}\text { Power is vested in } \\
\text { relations among } \\
\text { persons }\end{array}$ \\
\hline
\end{tabular}

Most governments give their aid on a bilateral and some indirectly through multilateral basis. The roles of donor agencies also extend beyond giving aid, donors also carry out economic analysis and reporting and encouraging further cooperation from the international community (Cassen, 1994). Donor countries have many reasons for giving aid, Alesina and Dollar (2000) says that the direction of aid is mostly dictated by political and strategic considerations. Foreign aid was used for four main purposes, diplomatic, developmental, humanitarian relief and for commercial purposes (Lancaster, 2007).

Colonial pasts and political influences are also major determinants of foreign aid (Alesina \& Weder, 1999). Some donors give aid to further their economic interests. Those that receive aid are mostly from developing nations. Foreign aid are given to recipients based on need considerations however, previous studies argue that donors do not strictly follow this objective (Clark, 1992). Foreign aid is intended to transfer resources that the recipient countries can 
use for the promotions of economic development and poverty alleviation. Aid have had successes in promoting growth in some countries, in others it has failed or even been counterproductive (Graham \& O'Hanlon, 1997). Much of the aid has been ineffective because aid agencies are trying to do lots of things all at the same time as a way to mark their presence in many places. It is mostly to satisfy the donor agencies goals rather then do what is best for the recipient country (Easterly, 2006). Some say aid failure is in the unsound economic policies the donor's support that further perpetuates poor policies and weak economic performance (Booth, 2012).

\subsection{High Level Forums for Aid}

To improve the effectiveness of aid the OECD initiated four High Level Forums (HLF) between 2003 and 2011. The first was held in Rome in 2003, then in Paris in 2005, Accra in 2008 and Busan in 2011.

Table 4 - OECD High Level Forum for Aid Effectiveness

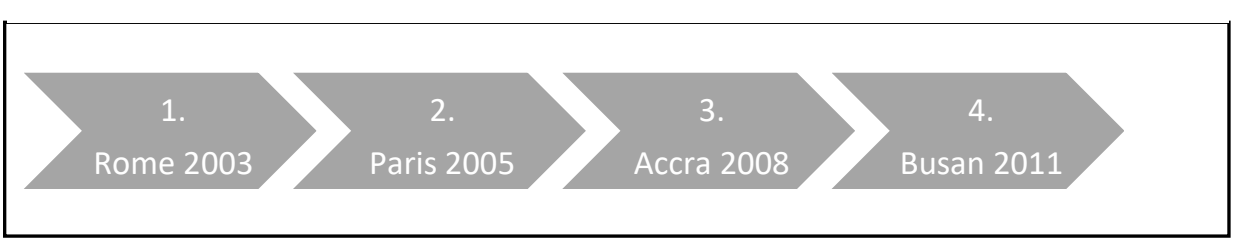

\subsubsection{What is Aid Effectiveness?}

Aid effectiveness is about value for money - it is about managing aid in a way that maximises its impact on development. Development donors and recipient countries have made many commitments. Commitments to the donors own taxpayers, to each other for the progress on development. Hence, aid effectiveness is about delivering on those commitments. 
The issue of aid effectiveness has re-emerged over the last few years as donors and recipients continue to seek ways to making aid more accountable and to improve on delivery approaches. There is a long debate about the tension between the multiplicity of development partners delivering aid assistance in a 'consultative and participatory' manner and the recipient country's ability to absorb the assistance offered (PIFS, 2005).

Has aid been effective? This is a question that's been asked over time and always there are opposing arguments of those that are anti-aid and those that are pro-aid. Many believe the weakness in aid effectiveness are planners at the top that do not listen to the poor at the bottom, that the results do not reflect the spending (Easterly, 2006). Aid is usually lost mid-way in the process without reaching the intended recipients and at most times no one is held accountable for these failures. Each donor have different donor requirements adding to the already burdensome administration of the recipient countries coupled with the transaction costs (PIFS, 2005). The performance of aid varies from country to country and from sector to sector. A lot of people have said aid has made matters worse in countries.

Dambisa Moyo in her book 'Dead Aid' states that "aid has helped make the poor poorer, and growth slower" (Moyo, 2009, p 1). This may be true in some countries and it is difficult to differentiate why aid in some countries has not produced any progressive results. Even though governments work hard to improve all their systems they are still trapped in a cycle that is dependent on foreign aid and it is difficult to determine why this is still happening. Donors often have political and commercial motives in giving aid and sometimes 
these motives dominate and interfere with the purpose of aid. These interferences usually result in poor growth for the recipient countries. Though it is not all doom and gloom, there have been success in receiving aid. Before countries receive aid, development donors would advise governments of the necessary changes to their government systems, these changes are usually in the forms of governance frameworks and policy improvements. Recipient countries organising and implementing these are improving and building their efforts to make aid more effective.

Globally, the international community has signed up to three agreements to enhance aid effectiveness - the Paris Principles (2005), the Accra Agenda for Action (2008) and the Busan Partnership for Effective Development Cooperation (2011). In addition to these, PICs have also agreed on three other important regional mechanisms - the Pacific Plan for strengthening regional cooperation and integration (2006), the Pacific Aid Effectiveness Principles (2007) and the Cairns Compact on strengthening development coordination in the Pacific (2009).

\subsubsection{Rome 2003}

The Rome Declaration on Harmonisation marked the first high level forum (HLF) where the principles of aid effectiveness were captured. The forum was attended by over 28 recipient countries and over 40 multilateral and bilateral development institutions. All the parties that were present reaffirmed their commitment to eradicate poverty, achieve sustained economic growth and promote sustainable development (OECD, 2003). 
The Rome Declaration listed three priorities:

1. That development assistance be delivered based on the priorities and timing of the countries receiving it;

2. That donor efforts concentrate on delegating co-operation and increasing the flexibility of staff on country programmes and projects;

3. That good practice be encouraged and monitored, backed by analytic work to help strengthen the leadership that recipient countries can take in determining their development path.

It is recognised that harmonisation of policies, procedures and practices of donors and recipient countries are at the heart of the Rome Declaration. The declaration emphasised the need for a strong leadership role from recipient countries, and the encouragement of good practices. While ownership is highlighted it is only limited to governments. Other stakeholders such as civil society organisations (CSOs) or the private sectors were not recognised as important actors in the whole regime. After the Rome HLF some progress in harmonising aid was made, but development aid still focused a lot more on donor interests. Overall, the outcome of the Rome HLF was narrowly focused on technical and procedural aspects of aid (Tujan, 2013).

\subsubsection{Paris 2005}

The second HLF in Paris in 2005 developed an action-oriented roadmap to improve the quality and impact of aid on development. This roadmap together with five principles and building on the Rome Declaration formed the heart of the Paris Declaration on Aid Effectiveness. 
Table 5 - Principles of the Paris Declaration on Aid Effectiveness

\begin{tabular}{|l|l|}
\hline Ownership & $\begin{array}{l}\text { Partner countries exercise effective leadership over } \\
\text { their development policies, and strategies and co- } \\
\text { ordinate development actions. }\end{array}$ \\
\hline Alignment & $\begin{array}{l}\text { Donors base their overall support on partner } \\
\text { countries national development strategies, } \\
\text { institutions and procedures. }\end{array}$ \\
\hline Harmonisation & $\begin{array}{l}\text { Donors' actions are more harmonised, transparent } \\
\text { and collectively effective. }\end{array}$ \\
\hline Managing for Results & $\begin{array}{l}\text { Managing resources and improving decision- } \\
\text { making for results. }\end{array}$ \\
\hline Mutual Accountability & $\begin{array}{l}\text { Donors and partners are accountable for } \\
\text { development results. }\end{array}$ \\
\hline
\end{tabular}

Source: OECD, 2005

Paris produced 12 indicators to measure progress and each of these indicators had a specific target and was expected to be achieved by 2010 (OECD, 2011). The Paris Declaration states that country ownership is achieved when "partner countries exercise effective leadership over their development policies and strategies, and co-ordinate development actions".

It commits recipient or partner countries to three objectives of ownership:

- Exercise leadership in developing and implementing their national development strategies through broad consultative processes.

- Translate these into prioritised results-oriented operational programmes as expressed in medium-term expenditure frameworks and annual budgets (indicator) 
- Take the lead in co-ordinating aid at all levels in conjunction with other development resources in partnership with civil society and the private sector (Rakner and Wang, 2007).

\subsubsection{Accra 2008}

The third HLF in Accra in 2008 was a significant event. The inclusion and expansion of stakeholders from donor countries, emerging economies, UN and multilateral institutions, global funds and civil society organisations were all involved in the forum sighting a momentous time for development effectiveness. The third HLF concentrated on three aspects as stated in the Accra Agenda for Action (AAA) to help aid effectiveness. Ownership was one of the aspects which was highlighted in the Paris Principles but the other aspects included inclusive partnerships where all partners participate fully and delivering results that will have real and measurable impact on development. It was in Accra that the need for a multi-stakeholder framework was first brought to light and a major shift towards an inclusive process to enhance aid effectiveness (Schneider, 2013). Rome and Paris focused on governments when discussing country ownership and Accra was the first that brought in other stakeholders, ownership was inclusive and widened to include governments and CSOs (Accra Agenda for Action, 2008). To strengthen what was agreed in Paris the Accra Agenda for Action took stock of progress and focused on areas of ownership, partnership and delivering results. 


\subsubsection{Busan 2011}

The fourth HLF in Busan in 2011 was the first where CSOs were actively involved in the HLF platform. The Busan HLF concluded in the signing of the 'Busan Partnership for Effective Development Co-operation' which establishes the first time an agreed framework for development co-operation that embraces traditional donors, South-South co-operators, the BRICS (Brazil, Russia, India and China), civil society organisations and private funders. The Busan Partnership specifically highlighted four principles for all development actors to make development more effective. Ownership and a focus on results were highlighted in the Paris Principles and the AAA, and the two new principles were partnerships and transparency and shared responsibility. Partnerships where development depends on the participation of all actors, and recognises the diversity and complementarity of their functions, and transparency and shared responsibility where development cooperation must be transparent and accountable to all citizens.

The Pacific has significantly amplified its voice and participation in global discussions on development effectiveness. Only four ${ }^{1}$ PICs were represented in Paris in 2005 compared to eleven in Busan in 2011 (PIFS, 201). This is a sign that the Pacific is taking ownership of its development and growth.

\subsection{Pacific Islands and the Aid Effectiveness Agenda}

Pacific people are custodians of the world's largest ocean and a rich diversity of cultures. For the purpose of this research the Pacific region comprises of

${ }^{1}$ PNG, Solomon Islands, Vanuatu and Fiji. 
15 countries $^{2}$. These Pacific Island countries (PICs) spreads across a very large geographical area, they differ in size, population, resource base and development constraints and prospects. But what they share in common is the rising economic vulnerability (ADB, 2011).

Small population sizes and dispersion over vast areas are both a curse and a blessing for PICs. It is a curse because of the diseconomies of scale that hamper development efforts. Transport costs are high and markets are small, industrialisation remains minimal and specialist human resources are few. These factors cause many PICs to rely on subsistence activities outside the monetary economy. Hughes (2003) identified PICs as being poor and slaves to their colonial pasts. She claimed that the island clans and communalism loyalty are seen as a hindrance to development. However strength is within the strong family and tribal ties which form effective social safety nets.

Countries in Oceania are amongst the highest per capita recipients of aid globally (Overton, 2011). The OECD DAC highlights Oceania region (comprising 22 island countries and territories) as the highest per capita recipient of development aid globally - standing at US\$237 per capita, about 4.8 times more than the African region (US\$49 per capita) and almost ten times more than the global average for aid to all developing countries combined (US\$24 per capita) (Rodgers, 2013). Evidence indicates that the importance of aid is seen largely within the context of economic growth rather than poverty reduction. Just over $90 \%$ of all aid flowing into the Pacific comes

\footnotetext{
${ }^{2}$ Cook Islands, Federated States of Micronesia, Fiji, Kiribati, Marshall Islands, Nauru, Niue, Palau, Papua New Guinea, Samoa, Solomon Islands, Tokelau, Tonga, Tuvalu, and Vanuatu.
} 
from five DAC countries - Australia, France, Japan, New Zealand and the USA - and one multilateral partner, the European Union (Rodgers, 2013).

Figure 3 - Total Aid Flow to Pacific Islands from NZAID

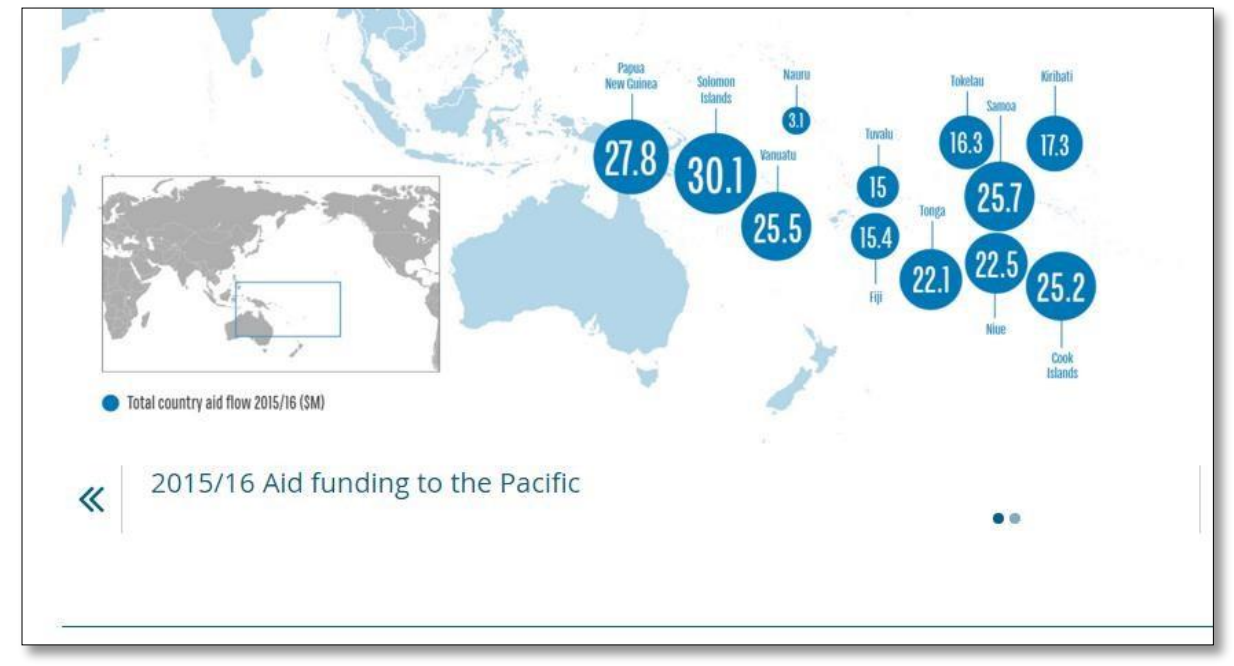

Source: www.mfat.govt.nz

According to some estimates the Pacific is one of the slowest-growing regions in the world meaning that it is going backwards rather than forwards (PIFS, 2014). The effectiveness of aid to the Pacific region has frequently come under discussion, for many the high volumes of aid have not translated into significant improvements in economic growth and other development indicators. Effectiveness of foreign aid to the Pacific islands is a serious concern, for majority of the PICs foreign aid has played a major role in supplementing government budgets. People living on small islands generally understand their own islands and how to build resilience to cope with significant changes. For many years, the Pacific community and other agencies have worked together to strengthen resilience (PIFS, 2007). But defining development effectiveness in the Pacific context refers to the relative 
strength of development assistance and development cooperation in achieving the goals and objectives of each nation (PIFS, 2007).

The Pacific has come a long way from its colonial pasts, and is working tirelessly towards self-sufficiency. It is an ambitious goal for islands each with their unique challenges but Pacific islands are exerting stronger leadership and ownership of their development agendas (PIFS, 2011). The previous director general to the South Pacific Community (SPC) in his Small Islands, Big challenges: rethinking the Pacific aid architecture have said that, "In the future, will all Pacific islands countries reach a state of economic selfreliance where they will no longer require development aid to supplement their own development efforts? The reality is that very few Pacific countries have this potential. Even for these few, it is unlikely they will achieve such level of self-reliance in the short to medium term. For the majority of the 22 island countries and territories, dependence on development aid will continue in the long term. For some it will remain a permanent feature of their development agenda" (Rodgers, 2013).

The Pacific has dealt with multiple development agencies, each with its own list of procedures to follow. The growing interest in the Pacific region internationally and the recognition of the region's potential, shows the Pacific must ensure the best is retrieved. The leaders of the Pacific recognising this tension have agreed on a set of principles namely the Pacific Plan for strengthening regional cooperation and integration (2006), the Pacific Principles (2007) for aid effectiveness and the Cairns Compact (2009) on strengthening development coordination. 


\subsubsection{Pacific Plan for Strengthening Regional Cooperation and Integration 2006}

The Pacific Plan was designed to strengthen cooperation and integration between PICs. Leaders at their meeting in Auckland in 2004 agreed on the following vision that "the Pacific region can, should and will be a region of peace, harmony, security and economic prosperity, so that all of its people can lead free and worthwhile lives..." The Pacific Plan was recognised as a high-level framework for priority setting for each national government. The central idea of the Plan was for PICs to work together and achieve government's respective goals.

The Pacific Plan was built on four pillars that was geared towards enhancing economic growth, sustainable development, good governance and security for the Pacific through regionalism (PIFS, 2013). It was updated in 2009, with 37 priorities, grouped under five themes: fostering economic development; improving livelihoods and well-being; addressing climate change; strengthening governance; and improving security. The Plan is based on the concept of regionalism, countries working together for joint and individual benefits, but does not limit countries sovereignty. The intention was to complement and support national development plans. The policies developed under the auspices of the Plan has been slow, that it was not making much difference. One major setback of the Plan is that it was not known widely beyond its immediate stakeholders. It also had a lot of priorities and carries no powers of enforcement, there was also no budget to implement the plan and indicators to show its successes. 
The Pacific Plan underwent a review in 2013 involving visits to all 18 member and associate member countries of the Pacific Islands Forum. This review was one of the "most substantive consultations about contemporary Pacific issues" ever executed (PIFS, 2013, p 2). The review presented consistent activities in the region, that islands are experiencing significant social, economic, environmental change and challenges. Henceforth a push from Pacific citizens for a stronger political will. There was strong support for a high level political forum to debate issues which extends towards sensitive topics such as sharing sovereignty, national priorities will not always be reflected or supported in regional priorities (PIFS, 2013).

\subsubsection{Pacific Aid Effectiveness Principles 2007}

The Pacific Aid Effectiveness Principles (PAEP) were derived from the Paris Declaration on Aid Effectiveness. The Pacific Principles were widely consulted across the Pacific region and it was tailored to fit the Pacific context. The eight Pacific Principles are:

1. Country leadership and ownership

2. Multi-year commitments by development partners \& aligned to national priorities

3. Greater Pacific ownership of regional development

4. Development partners and countries pursue a coordinated approach...encouraging harmonisation

5. Strengthened institutional mechanisms and capacity in countries in enable increased use of local systems

6. Provision of technical assistance that ensures capacity is built and benefits are tangible to support national ownership 
7. Short term technical assistance addresses local skills gaps and are culturally sensitive

8. Use of agreed monitoring and evaluation framework that will ensure joint assessments

Before 2005 aid flows to the Pacific were highly volatile, coordination between donors was fragmented and there was a lack of consistency between donor activities and national priorities (Tangi, 2012). There were also inconsistencies between donors and the excessive demands on local resources. However the Paris Declaration and the Pacific Principles has given a guide for the PICs to manage aid as well as monitor the performance of development partners to ensure best results. The Pacific principles have enabled the Pacific islands to determine for themselves what their feasible priorities are and to make its position clear to development partners (Tangi, 2012).

\subsubsection{Cairns Compact 2009}

The Leaders adopted the Cairns Compact with a vision that it will foster new and invigorated commitment to improve the economic and development performance of the region. This came about after the Leaders expressed deep concerns that the Pacific region despite the high levels of development assistance over many years it seems that the region is still off track to achieving the MDGs by 2015. The aims of the compact were to improve national planning, budgeting and aid coordination and processes. The guiding 
principles to foster and drive a coordinated approach to the compacts implementation were:

1. Private sector led growth, essential for achieving faster development progress

2. Improved governance and service delivery are essential to achieving faster development progress

3. Greater investment in infrastructure underpins greater economic development

4. Country leadership, mutual accountability and responsibility between FICs and Development Partners are fundamental to successful development outcomes

5. Need to draw on international best practices expressed in the Paris Declaration, Accra Agenda of Action and the Pacific Principles on Aid Effectiveness

6. A revitalised commitment to the Millennium Development Goals

The Forum compact has been the region's key response to the international development effectiveness agenda (PIFS, 2014). It was envisioned to provide backing for better coordination and more effective delivery of development assistance and to streamline and consolidate existing national and regional processes aimed at improving coordination and delivery of development assistance and resources. It was envisioned that the compact will continue to be a key Pacific regional mechanism for coordinating development assistance into the future. But as always plans and agreements are instruments of their 
time. The compact now is not apparent in country planning and negotiations for development.

\subsection{Summary}

The issue of aid effectiveness has re-emerged over the last few years as donors and recipients continue to find ways of making aid more accountable and to improve delivery approaches. Nearly all Pacific Islands have national development strategies, but only those with relatively good capacity and experience are able to use it to shape the sector activity and budget exercises to align with country priorities and development partners. Effectiveness of foreign aid to the Pacific Islands is a serious concern, for the majority of the PICs foreign aid has played a major role in supplementing government budgets. The Paris Principles (2005), Accra Agenda for Action (2008) and the Busan Partnership for Effective Development Cooperation (2011) are agreements the international community have pledged to enhance aid effectiveness. In the Pacific similar pledges have been introduced which includes the Pacific Plan for Strengthening Regional Cooperation (2006), the Pacific Aid Effectiveness Principles (2007) and the Cairns Compact on Strengthening Development Cooperation in the Pacific (2009). These mechanisms were designed not only to enhance aid effectiveness but to move away from the top-down neoliberal approach that saw the donors taking the lead in aid development. We may criticize where aid has failed but we also need to build where it has succeeded and what new initiatives show promise rather than dismiss. 


\section{CHAPTER 5: IMPLEMENTING THE AID EFFECTIVENESS AGENDA IN NIUE}

\subsection{Introduction}

The aim of this study is to analyse and critique Niue's aid programme. It is not to judge Niue's spending instead it is to highlight ways in which Niue can strengthen its aid policies and make it more effective. This chapter is structured around an evaluation using only four of the principles of the Paris Declaration which are ownership, alignment, harmonisation and mutual accountability.

It will present the findings from the Niue Peer Review for Strengthening Development Coordination conducted in July 2011 (PIFS, 2011) and it will be followed by findings from semi-structured interviews held with government officials (respondents A to J) during field research in July 2016. Even though the purpose of the Paris Declaration is to improve the relationship between development donors and recipient governments, it is used in this context to evaluate the relationship between the government and the different departments in Niue. These principles provide a common agenda for global and for national level dialogue on aid effectiveness.

\subsection{The Principle of Ownership}

Ownership have had its fair share of criticism. The Paris Declaration and how the principles were to be implemented was endorsed by a number of national governments and various multilateral agencies. The principle of ownership talks about development donors to 'respect the right and responsibility' of the recipient countries to make their own development agendas, set their own strategies for poverty and for growth (Rogerson, 2005). But it is crucial for 
this to be articulated by governments themselves, to present a clear statement of development. Creating national development strategies with clear strategic priorities, an important indicator for ownership. The question to ask is, does Niue have ownership of its aid programme? The answer is yes, but to a certain extent. Let me elaborate on the level of extent.

The Niue Island Strategic Plan (NISP) from 2003 - 2008 was an arrangement between the Government of Niue and the Government of New Zealand. The NISP documented Niue's priorities at that particular period of time. With every plan there are successes along with issues and challenges associated. The NISP 2003-2008 during the consultation phase was not widely known or articulated to all stakeholders. The NISP only consulted with the government departments. "Unfortunately there was not very much consultation with government departments at that time, it was just pressured for time. Basically we had to put something together, we came up with a document together that saw might fit the bill, it wasn't the answer to all our prayers but it was what we saw best at the time, these things are works in progress" (Respondent, F).

The Niue National Strategic Plan (NNSP) from 2009 to 2013 was the first official strategic development plan for Niue (Respondent F interview). The NNSP 2009-2013 contained six pillars and each pillar had its own set of strategies. There were 38 strategies altogether and each of these 38 strategies had its own set of targets and indicators. There were at least 100 targets for the government to achieve. The NNSP 2009-2013 have made improvements from the previous NISP 2003-2008 plan whereby the NNSP 2009-2013 was 
shorter in length. It NNSP was more action oriented with some clear measurable targets and indicators and it clearly showed the lead agency for each strategy.

Table 6 - Niue National Development Pillars 2009-2013

\begin{tabular}{|l|l|}
\hline Financial Stability & $\begin{array}{l}\text { Ensure that sufficient financial resources are secured, and } \\
\text { responsible fiscal management is prudent, sustainable and supports } \\
\text { healthy development strategies }\end{array}$ \\
\hline Governance & $\begin{array}{l}\text { Ensure that good governance reflects the principles of } \\
\text { transparency and accountability and is practised at all levels }\end{array}$ \\
\hline Economic Development & $\begin{array}{l}\text { Maximise benefits from Niue's resources in a sustainable manner } \\
\text { focusing on private sector development, targeting tourism, } \\
\text { agriculture and fisheries supported by safe, reliable, affordable } \\
\text { healthy infrastructure }\end{array}$ \\
\hline Social & $\begin{array}{l}\text { Enjoy harmonious and healthy lifestyle in a thriving, educated and } \\
\text { safe community that has access to a wide range of quality social } \\
\text { services and healthy development opportunities }\end{array}$ \\
\hline Environment & $\begin{array}{l}\text { Sustainable use and management of Niue's natural resources and } \\
\text { environment for present and future generations }\end{array}$ \\
\hline Taoga Niue & $\begin{array}{l}\text { Promote, preserve and strengthen Niuean cultural heritage, } \\
\text { language, values and identity }\end{array}$ \\
\hline
\end{tabular}

Source: GON, 2009

Individual corporate plans for all departments are said to align to the NNSP. How the linkages are articulated between plans showed another uncertainty. When interviewing respondents about the how the linkages of alignment is organised and structured, most of them were unsure. One because each department were working with its own format of corporate plans thus making it difficult to gauge the level of progress. Some of the respondents acknowledged that the department corporate plans required a lot of 
improvement, and the response were establishing a committee to focus on preparing a new corporate plan template for all departments to follow. Consultations and education workshops were held on how to use and understand the new corporate plans.

The department for Economic Planning, Development and Statistics (EPDS) was the department dedicated to monitor and review the NNSP but due to staff capacity and the reshuffling of responsibilities the monitoring and review did not materialise. "Our problem is there's no one monitoring our national plan, we need to do a mid-term review to see what's been achieved and what's not. But no one is doing that" (Respondent G).

There were mixed observations from the respondents on the monitor and review of the NNSP. All respondents claim the review is done annually when each department submit their annual budgets to the legislative assembly. What is interesting is not all respondents know exactly how the review is done using the department budgets. For most it seems they were agreeing with the status quo because it's safe.

A peer review of Niue's national development processes under the Cairns Compact on strengthening development coordination conducted by the Pacific Island Forum in 2011 found similar conclusions (PIFS, 2011). Only a few of the private sector knew of the NNSP and surprisingly some only had sighted the NNSP only once while others had never seen it before.

A recommendation from the review was for the government to strengthen the capacity of EPDSU as the technical arm of government to facilitate and 
coordinate the implementation and coordination of the NNSP. The technical capacity was to go hand in hand with the investment and development budget of government (PIFS, 2011, p 20). The better capacity of EPDSU will enable the government to undertake a mid-term review of the NNSP. This would be an opportunity for government to further review its strengths and weaknesses and decide where to refocus efforts.

Ownership encourages greater responsibility at the country level and less intrusion and imposition from development donors. Ownership was aimed at establishing a more balanced relationship between the recipient countries and the development donors. There are concerns over the implementation of Niue's development strategy. There is strong ownership in designing the strategic plan with a strong long-term vision, however the weakness is in the operationalisation of the NNSP. "That's one of the major problems we have here in Niue is the fact that there is so many competing priorities that sometimes the government find it very hard to fixate on one particular theme for a particular length of time, there's always competing interests therefore they keep shifting, they keep moving the priorities" (Respondent, F).

The concept of ownership in the Paris Declaration requires a relatively strong internal coherence and good capacity at all levels to effectively coordinate aid. Coherence and capacity are two complication in Niue's efforts toward aid effectiveness. "We are working with donors and donors requirements, when it should be the other way around. Sometimes it's unfair when we are penalised over rules of procedures even if the outcome is achieved, but only because we didn't follow the rules" (Respondent $G$ ). 
I believe that ownership is not a product of financial aid but a prerequisite for it. Therefore there should be a national will from all levels to accept the responsibility for its own development. Once this is established external aid can assist to bring the development aspirations of Niue to fruition. Ownership in itself is a goal for governments to strive for but not something that just needs to be recognised. "Sometimes it feels like Niue takes the easy way out. We complain about our capacity issues but we don't do anything about. Sometimes we use capacity as an excuse, that's why we're not moving forward, when we should just all come together and work together" (Respondent, $G$ ).

\subsection{The Principle of Alignment}

There are two types of alignment I will be discussing in this section, policy alignment and systems alignment. Policy alignment ensures that donor assistance aligns with the national development strategies. This is important because it encourages policy dialogue and reviews, which is important to assess the progress of development plans (Foresti et al, 2006). If governments do not have the necessary capacity at the policy level, then the focus is on creating the space and an enabling environment for this capacity to emerge instead of securing donors to cover for this gap.

The Paris Declaration commits development donors to align its agenda with recipient country policies and systems for the delivery of its assistance (OECD, 2005). This also means development donors modifying their assistance to align with the priorities of the recipient country. The donors align their development assistance with the development agenda and 
strategies set by the recipient countries and to utilise the recipient countries local systems of financial management. At the same time it will enable recipient countries to strive to improve its financial management systems (Rogerson, 2005).

System alignment describes the commitments by development donors to use and strengthen country's institutional systems and procedures, with particular reference to public financial management and procurement systems (Foresti et al, 2006). The Niue investment and development budget was idolised as a step towards better management of funds received by Niue (PIFS, 2011). The government of Niue have completed its public expenditure and financial accountability (PEFA). The goal was to provide greater clarity and transparency for Niue and its development partners (PIFS, 2011). Development aid to Niue from New Zealand is channelled through general budget support, program support for things such as asset maintenance, technical assistance, Niue Trust Fund and through projects (PIFS, 2011). A large amount of funds from New Zealand paid to Niue is disbursed through Niue's national systems. "This reinforces the relationship between Niue and New Zealand. I can confirm New Zealand uses our systems. A very encouraging and positive outlook" (Respondent, $\mathrm{H}$ ).

Other contributions such as the Niue International Trust Fund made by Australia and New Zealand also meet aid effectiveness standards of low cost transactions and availability of the proceeds contribute to Niue's budget (PIFS, 2011). "Donors needs to be confident with the government financial 
systems. They'll need to be confident, if they aren't and of course they'll run and have ownership of the project. How much they give you also depends on how they see your financial systems" (Respondent C).

There are a lot of literature on alignment of aid with country policies. Problems arise when short term political needs overshadow the country policies (Booth, 2012). "This is one of the hardest parts in doing projects, we get caught in the middle and sometimes we don't know what to do whether we follow our Minister or follow the project work plan. Most of the time we have to listen to our Minister" (Respondent K).

A recommendation of the PIFS review was the establishment of the aid management unit (PIFS, 2011) to manage and coordinate development funds for the government of Niue. This unit have recently been established and it is still in its embryonic stages. The location of the unit within the government is important strategically and it has been a subject of difference between government officials. The unit is currently housed within the Office of the Premier. However in the report by PIFS (2011) location within EPDSU can be helpful in emphasising the links within departments as well as between development donors.

\subsection{The Principle of Harmonisation}

The Paris agenda on aid effectiveness emphasises support for recipient owned development strategies as well as the use of national systems. The most significant progress achieved at the Paris forum was the agreement in principle on a set of targets that can be monitored (Rogerson, 2005). The Rome Declaration on Harmonisation (2003) identifies the importance of 
harmonising policies, procedures and practices of development donors with the recipient governments systems in order to improve effectiveness and thus achieving the MDGs. In practical terms harmonisation is illustrated in the aid effectiveness pyramid below. Harmonisation efforts are encouraged because it contributes to the strengthening of the relationship between the government and its citizens entailed in the mutual accountability commitment especially when recipient governments deal with many development donors (Foresti et al, 2006). The principle of harmonisation looks at all these support then coordinate and simplify these actions to avoid duplication and overburdening on the recipient countries.

Figure 4 - Aid Effective Pyramid

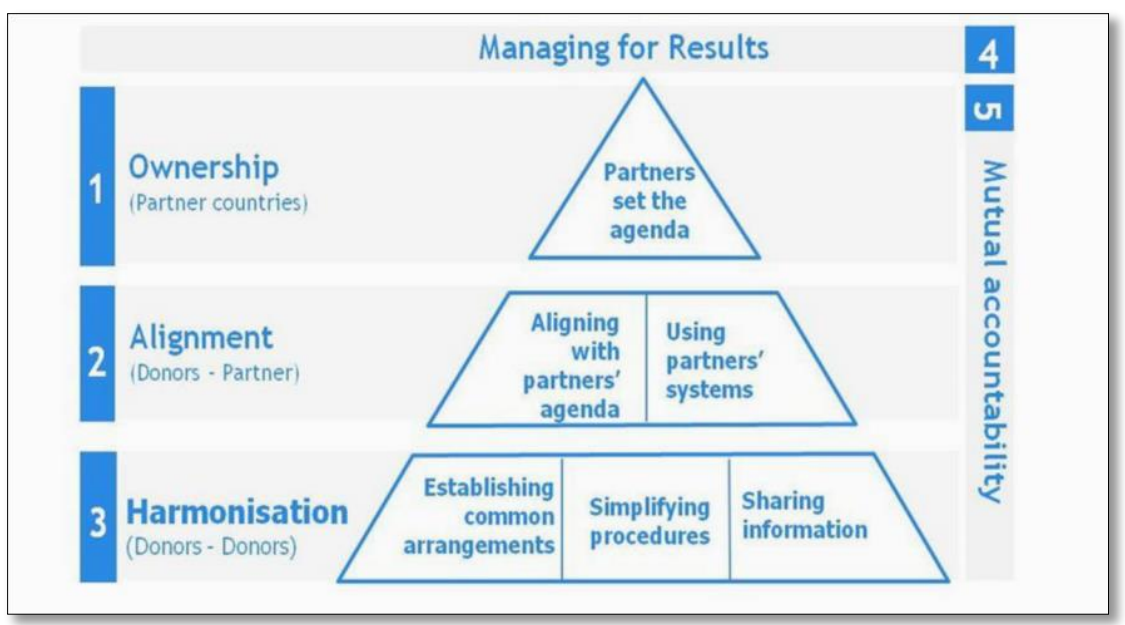

Source: OECD (2004)

Niue manages a large number of projects with the associated monitoring and reporting burden (PIFS, 2011). What is complicated in Niue's case is that the donors are harmonising their practices for effective aid delivery to make it easier for Niue, however the Government of Niue is behind in its efforts to be proactive with the plans for effectiveness and efficiency for aid development. 
The Government recognises what needs to be done but the problem is where to begin and who to spearhead it. Everyone is consciously saying it is the role of the aid management unit, but because the unit is new its harmonisation efforts are not well established.

\subsection{The Principle of Mutual Accountability}

In a perfect world, foreign aid will be more effective in delivering results when there is country ownership and the relationship between donors and recipient governments are based on shared values, and the frameworks for mutual accountability. Progress on mutual accountability at country and international levels are uneven. There are concerns around the disconnect between policy and practice (OCED, n.d). Historically, donors have held recipient governments accountable for how aid money was spent and often these are accompanied with conditions and majority of the time donors are not accountable to the recipient governments (OECD, n.d). There is a need to balance this aspect. Mutual accountability emphasises reciprocal commitments to enhance aid effectiveness. On the recipient countries this is done by strengthening the role of parliament and strengthening participatory approaches to policy making, monitoring and implementation. On the donor's side, it is focused on the transparency of information and aid flows. These conditions have come under criticism for their lack of effectiveness and at times an 'infringement of sovereignty' (Foresti et al, 2006).

In many aid dependent countries strong accountability for the use of aid funds goes from recipient governments to donor agencies, and from donor agencies to donor country parliaments and citizens. "Some people don't want to work 
with certain donors because their procedures too hard. We can't change donor rules, we just need to go with it, cos even the donors need to account to someone so I just have to accept it. Accept it or you'll lose out. Sometimes we have to change our ways to suit the donors" (Respondent G).

The Paris Declaration makes little mention of recipients' domestic accountability, while this is recognised as one of the main obstacles in achieving higher degree of accountability in aid relationships (Foresti et al, 2006). The accountability of the departments within the government of Niue is a constant battle. "As a matter of practice and a matter of cause, we should aspire to accounting properly for the money we get. It's only fair these people come by their money by hard work and we need to show that we can properly spend it and account for it. And to achieve the things we want to achieve. Even when we spend our own money we should account for it. But there is a tenancy here that once we get that, that's it, we got it, don't worry about it. Any reporting after don't worry. That same attitude is reflected in government departments nowadays which don't submit their annual reports. They've got to account for how they spend their money they got for the year that was allocated by the Niue Government in the budget but they don't, there's very little reporting from the departments in relation to that, they've done the work the issue now is...ok what did you do? what did you spend? That's where we keep falling down, I don 't know why" (Respondent F).

To have strong ownership of development plans communication is key. Communication between government departments requires a lot of improvement. The transformation of the government processes and structures 
have created confusion. There is tension between government officials because of the lack of consultation on the progress of the transformation. But this can go either way, it's either they do not receive the notifications that have been distributed or they are deliberately ignoring it altogether.

\subsection{Summary}

The best thing about this is Niue has strong ownership of designing its development strategies but at present lack ownership in the implementation of the plan. There are miscommunications on who or which department is supposed to be monitoring and evaluating the progress of Niue's development strategies. There are still huge levels of improvement required. There needs to be active collaboration from civil society, this group needs to be more involved. Another important step is to improve national capacity at all levels. Progress is monitored by mechanisms at country level which are refined and improved continuously. Eg. Annual Progress Reports, Improved statistical data collection, monitoring frameworks such as KPIs. More mechanisms should be in place and existing mechanisms should be strengthened. The Peer Review for Niue in 2011 also picked up on the lack of clarity in the governance framework for Niue's National Strategic Plan. The department that was supposed to undertake the review had capacity issues and the midterm review of the NNSP 2009-2013 that was planned towards the end of 2010 had not yet been done. The flexibility in the utilisation of funds is very important, especially for Niue where there are no large reserves available for the country to utilise. Priorities change relatively quickly and countries such as Niue don't have large reserves and therefore Niue utilise what's available it's not the best arrangement but it's the reality. Overall, the officials 
interviewed is fully aware of Niue's status of development coordination. Aid programs in the 1950s and 1960s was centred on economic well-being and defined their central mission as fostering economic growth. It was initially thought that economic growth in poor countries would produce political development. However it has also fostered another form of growth which is power. Some have concluded that development partners are no longer the solution but are also part of the problem; how development partners use their weight around has ramifications on how partner countries will fare with regard to such concerns as good governance and reduction of poverty. 


\section{CHAPTER 6: ISSUES AND CHALLENGES OF THE GOVERNMENT}

\subsection{Introduction}

The previous chapter presented the findings of the aid effectiveness agenda in Niue using the Paris Principles for aid effectiveness. Chapter six will discuss other issues and challenges that were shared by the respondents during the interviews. These challenges are factors the respondents perceived as critical to move forward with the government's aspirations. The challenges and issues are interesting because it was mostly around behaviour and inter-personal relations of public servants.

\subsection{Government Workers}

\subsubsection{Capacity constraints}

Capacity constraints are highlighted as one of the key factors that hamper aid and development in Niue. The struggle with a low population and the downside of having such a low population are finding the people with the capacity to undertake jobs. Government officials are stretched with responsibilities and the unrealistic expectations to meet deadlines donor responsibilities and activities overlap and dealing with multiple development partners and projects leaves government officials ineffective and stressed. The establishment of a projects management coordination unit (PMCU) under the Premiers office has assisted toward eliminating some of the overlap. 
There are current tension with local officials when engaging consultants to work on projects in Niue. The tension originates because "we're losing our own people in getting consultants. There is no continuity with these people. They network on our behalf and when they leave they take these networks with them. Niue loses out" (Respondent A).

There is also the tension within the government departments themselves "we don't recognise the value of our own people, we don't listen to what our people are saying until you have problems" (Respondent A). This is interesting because it reinforces the prevailing view in Epeli Hau'ofas (1993) article about Pacific people actively propagating the idea of the islands as too small, too poor with resources and depending largely on wealthy nations. Hau'ofa (1993) went on to say that Europeans did not create belittlement, it was already part and parcel of Pacific cultures. Which doesn't surprise me that Niue covertly exercise these Western constructs, of Europeans and expatriates know better.

The idea of promoting people to higher positions because of their long services to the government occurs in Niue. "We need people who takes initiative to make things move, to think outside of the box. Having the right people in the right places is immense because it has a positive domino effect on the rest of the sector. But not simply putting people in positions because they've been there for a long time" (Respondent F). It is known that such operations do not work effectively, it is blind loyalty therefore judgment becomes blurred (Leonard and Strauss, 1997). 
One of the schemes the government is undertaking is called the revolving programme for new graduates. The graduates are placed in a six month revolving programme administered by the Niue Public Service Commission (NPSC). The graduates rotate between departments usually on a quarterly basis for the first year of service. The programme was established to give the graduates an indication of the department operations, and after the scheme graduates can recommend their placement within their department of choice. Not always do graduates end up in their recommended places. The scheme has had some positive feedback while other graduates are against it because they say it drags the process or time for them to get started in their permanent positions.

\subsubsection{Implications for Speaking Out}

Participation, empowerment and mutual respect enables people to express and analyse their individual and shared realities (Chambers, 1997). Research on development increasingly emphasises the importance of participation. The language of democracy is highly encouraged in development circles. At national levels this is good governance, and at project level it is labelled as participation (White, 1996).

Voice within organisations offers leaders an adaptive capacity (Dutton \& Ashford, 1993; Floyd and Wooldridge, 1996). These voices should be seen as input to the organisations for decision making and it provides the organisation with emerging issues and room for improvement. Participation means the voiceless gains a voice, but even this can create conflict because this voice 
challenges power relations. As a respondent said "every time I voice my opinion I always get shut down' (Respondent B).

Participatory efforts are no panacea, but it unlocks ways of tackling challenges. White (1996) says if there is an absence of conflict we should question what interests and welfare is being suppressed. Public debate and engagement will generate greater demand for policymakers to actively pursue the right kind of development outcomes (Brien, 2013). This will enhance the policy dialogue.

\subsubsection{Vested Interests and Behaviour}

Vested interests are normally associated with negative overtones of being unfair, has self-interests and anti-social behaviour. Everyone has interests, and each person pursues these interests differently either individually or with people who are like-minded. Vested interests are not unethical, it is only unethical when it creates substantial inequalities within the general public (James, 2014).In an open, democratic society this pursuit is natural and acceptable. Self-interest specifies to be an influential determinant of behaviour that influences people's actions and opinions (Miller, 1999). Personalities and individual characteristics are fundamental factors in the success or failure of Niue's development as stressed by many respondents. However, there are many concerns around attitudes of officials by way of "why do more when you can do less and still get paid the same" (Respondent F). 
There is tension between departments because "personalities clash, it's hard to get information because of some people's territorial attitudes" (Respondent G). Other concerns are around the new recruits who are exposed to poor work ethics of some of the existing workers, "showing up to work late, driving around, playing games at the workplace and not bothered when senior officials or even the cabinet minister show up" (Respondent F).

\subsubsection{Politics and Aid}

Critics of foreign aid have long argued that poverty reflects government failure and aid is used as leverage by developed nations to impose neoliberal reforms (Boone, 1996). Ncayiyana (2007) suggests that aid should be decoupled from politics. Nonetheless politics has been an overlooked area for engagement, because aid can teach us about political regimes in recipient governments. Although politics and development assistance have had an uncomfortable and confusing relationship, a certain degree of political awareness is important for all aid programs.

In the Pacific, politicians were criticised for being slack and for their nonperformance. Also the political party's they represented had no strong ideological positioning (Brien, 2013). In addition politicians in recipient governments are mostly concerned with showing tangible, immediate results (De Renzio et al, 2005). Brien (2013) have also concluded that aid from one "government to another government is more than an altruistic form of charity, it is complex and entangled in the unwieldy political web of both donor and recipient governments". 
Politics and aid has both its advantages and disadvantages. For Niue, political leadership in the international arena is immense and the leaders of Niue have been working continuously to ensure Niue's voice is heard. Politics in aid is worthy when the political authority is utilised to push agendas and activities that are difficult at the officials' level. The political authority can also sway and fast track negotiations with regional organisations. The Premier of Niue in his 2015 interview on tourism, regionalism and Niue's quest for selfsustainability says, "We've got to be careful about the fact that we've focused our attention so much on the concept rather than the practical application of what that actually means to the Pacific island countries, and to the people that we serve...it appears to me that regionalism is a concept that many people talk about, but I'm not certain whether there is any practical implementation thinking in relation to what this regionalism can do, not just with small island states like Niue, but also some of the bigger island states that are part of the Forum".

Yet there are also difficulties where ministers sign and commit governments to global and regional declarations and these efforts go the opposite direction when pressures from other politicians to do something different. Politicians have also been criticised of micro-managing activities, they prescribe how the funds are to be used in project implementation. The officials in Niue government struggle to manage the directive of the politician against an agreed working plan with the development donor funding the project. These occur primarily because politicians may not be very familiar with the intricacies of aid development (Brien, 2013). Politicians adjust government 
policies to receive aid flows have also been critiqued, "we have also relaxed our local requirements to fast track the development assistance, when the terms and conditions needs to be balanced and to respect the development needs of the government" (Respondent C).

Aid whether short-term or long-term has played a key role in maintaining political stability (Sachs, 1994). For small Pacific islands politics and development aid is inevitable.

\subsection{Government Transformation Process}

The aim of the transformation for the Government of Niue is to improve service delivery considering the Government of Niue has been operating in its current infrastructure based on a model and framework established in the 1960's and early 1970's (GON, 2011). The transformation process was a refocus on a whole of government system to ensure new department functions are better streamlined and a redistribution of functions to remove any overlap of department responsibilities. The process also includes developing and reviewing appropriate legislations and regulations (GON, 2011). The transformation is still in progress and it has not been a smooth transition, these are some of the reasons why. The transformation has not been welcomed by everyone in government. There are officials who oppose the change because they are comfortable with the status-quo and are threatened with the unknown the transformation brings. But other officials who are in support of the process are saying, "some people find it hard to change and adapt, but either you give it a go or don't be part of it" (Respondent G). 
Standard operating procedures (SOPs) are a set of instructions compiled by an organisation to help workers carry out routine operations. The set of SOPs aim to achieve efficiency, uniformity and quality output while reducing miscommunication and failure to comply with regulations (Arkya, 2012). Like developing its country strategies and plans, Niue government is very strong but in implementation needs improving.

One of the main institutional factors in departments is its organisational structure. The organisation structure determined how roles and responsibilities are defined and shaped, how reporting and accountability lines work, and who has decision-making power over what (De Renzio et al, 2005). Defining clear and direct lines of responsibilities is important but it has not resulted as planned for the government of Niue in its transformation process. It has created confusion for government officials, "the transformation was supposed to help but it's just created havoc. Its created layer upon layer and new positions" (Respondent B).

The transformation and the amalgation of departments into ministries has left officials confused on who's doing what. The roles and responsibilities for departments are not clearly understood as shared by some of the respondents saying, "Communication (i.e. information) are coming to us in dribs and drabs. It appears that different departments have taken on different roles. There's no cohesion between departments. No one is clear on the channel of communication. We need one point of contact" (Respondent A). 
The four-day working week scheme is one of the successes of the transformation. Government officials in this scheme work for four days and gets paid for five days. This was understood as a pay-rise type of concept for all public servants. The scheme will also support the officials in giving them more time to participate in community activities like beautification projects for villages. As a result of the 4 day working week the government has made some savings in power, savings in fuel for government vehicles and office supplies. The scheme still requires a lot of work regarding the essential services such as health department, education department, police and telecommunication that requires to be in operation as normal. Niue have made good progress of is NNSP, on economic development progress in the tourism industry has been noticeable with the additional fortnightly flight from New Zealand since 2012 and the increased numbers accommodation for tourists. The flights have shown an increase in the tourist numbers of 8,000 arrivals recorded in 2015 compared to the 2,800 in 2005 (GON, 2016). Niue have streamlined its corporate tax collection mechanisms and introduced the Niue consumption tax (NCT) (GON, 2016).

\subsection{Summary}

The Government of Niue have made significant achievements in the last few years. It was not been an easy journey for the government says respondents, but the positive results makes it meaningful. The tourism sector have made noticeable progress both in the supply and demand side. An additional Air New Zealand flight weekly since 2012 and the increase in tourist numbers and accommodation in Niue. Effective communication is important in 
conveying information and messages between the government and the public, and government and development partners. Overall, the respondents say that the transformation has provided a positive setting for the Government of Niue to improve the coordination and communication among themselves and with the development partners. There's a need for government departments to communicate more, needs to be more cohesive in its dealings. Changing attitudes and behaviours of people in government is a complicated and ongoing task and respondents acknowledge what is needed is putting people in places where they can influence a positive change. Well-seasoned officials are encouraged to inspire young and new recruits of government. Some of the respondents voiced their deep concerns around the recognition of the Niue people, not recognising the value of its people. But more importantly looking after its people to avoid burn out from goals and unrealistic expectations.

The next chapter will outline the New Zealand Aid programme in Niue and some of the changes it has undergone. 


\section{CHAPTER 7: NZAID IN NIUE}

\subsection{Introduction}

The previous two chapters looked at the aid effectiveness agenda in Niue. This chapter will look at how effectively the NZAID programme have applied the principles of the Paris Declaration in its relationship with Niue. Whilst the aim of the Paris Declaration is to improve the effectiveness of aid, it has also provided some leverage for reforming aid and changing how donors behave. The aid effectiveness agenda originated from negative evidence and past failures in aid relationships. Nonetheless it is positive that development donors are now allocating more resources towards aid effectiveness and generated valuable discourse on what is effective aid (Ridell, 2007; Kharas and Chandy, 2011).

\subsection{Aid Delivery in Niue}

The assistance from New Zealand continues to be 'a critical lifeline for Niue's development' (Liuvaie, 2009, p 142). The assistance from New Zealand has yielded some positive results but these positive results did not come easy because of New Zealand's heavy-handedness approach and bully boy tactics (Liuvaie, 2009). A lot of work has gone into improving the relationship between the two governments of Niue and New Zealand. The following are some changes to the NZAID programme policies and delivery in Niue.

There is a noticeable change in the working relationship, "the working relationship between us has improved tremendously. It's massive. It's because of the people that you see a drastic change in the relationship. It was 
extremely hard to do anything back then, everything was one way. Whenever we try to suggest something, we were always shut down" (Respondent $\mathrm{H}$ ). The officials in Niue Government and the New Zealand High Commission in Niue were attributed to this achievement. Respondents says it is the people that made a huge impact. There are passionate people on the ground, people with knowledge about Niue and its unique challenges, and the ability to accept and cope with the challenges. Some of these challenges are basic and straightforward in other countries but not in Niue, simple things such as shortage of building supplies because it missed the monthly boat from New Zealand because the island is heavily reliant on imported goods from New Zealand. It is encouraging that the respondents feel the longer a relationship between the government of Niue and New Zealand is now a partnership. A partnership where one is not superior to the other, and both accountable for activities in an agreement.

\subsubsection{The Joint Commitment Framework for Development}

The joint commitment framework for development (JCFD) was a high level document that outlined the mutual commitments between the Niue - New Zealand partnership and the agreed priority sectors that New Zealand's financial assistance was assisting with. The JCFD was signed in 2011 it was largely led by New Zealand, but there was consensus on the development framework from GON officials involved. The priorities outlined in the JCFD are summarised in the table below. 
Table 7 - Priorities in the Joint Commitment Framework

\begin{tabular}{|c|c|}
\hline Priority & Activities and Outcomes \\
\hline $\begin{array}{l}\text { Tourism } \\
\text { Increase economic } \\
\text { benefits from tourism }\end{array}$ & $\begin{array}{l}\text { - } \begin{array}{l}\text { Supporting the expansion of Niue's } \\
\text { Matavai Resort to accommodate tourist } \\
\text { numbers. }\end{array} \\
\text { - Providing } \$ 1 \mathrm{~m} \text { in } 2015 / 2016 \text { to promote } \\
\text { Niue as a tourist destination. }\end{array}$ \\
\hline $\begin{array}{l}\text { Economic Governance } \\
\text { Strengthen economic } \\
\text { governance }\end{array}$ & $\begin{array}{l}\text { Providing Niue with } \$ 2 \mathrm{~m} \text { in } 2015 / 2016 \\
\text { to help manage and maintain its existing } \\
\text { assets, and continue development of a } \\
\text { long-term asset management plan. } \\
\text { - Providing } \$ 7.5 \mathrm{~m} \text { in } 2015 / 2016 \text { to enable } \\
\text { the Niue Government to deliver core } \\
\text { services. } \\
\text { Providing the Niue chamber of comer } \\
\text { with } \$ 350,000 \text { in } 2015 / 2016 \text { to foster } \\
\text { private sector development. }\end{array}$ \\
\hline
\end{tabular}

The biggest achievement of the JCFD was the alignment of its goals with the NNSP. Another benefit is not only does it provide funding for specified areas but it also offers capacity and technical assistance by departments in New Zealand as part of their business. This arrangement however was not fully developed and has great potential, and offer a lot more support for Niue. Brautigam (2000) says that aid is most effective when it supports countries' own development efforts and policies to which leaders, officials and citizens of the nation are really committed. It is less effective when the policies are donor-driven (OECD, 2007). The JCFD was not welcomed at first by government officials, one because it was New Zealand led and the officials 
were unsure what the purpose of it was. Two, because it was not locally-led and driven they did not place such importance on it and this was apparent in its review. The JCFD was seen as another administrative, bureaucratic activity that is required to receive funding.

\subsubsection{The Forward Aid Programme}

The JCFD is the partnership agreement between the government of Niue and New Zealand outlining the agreed priorities and mutual responsibilities. These priorities are operationalised through the forward aid programme (FAP). The FAP is a three-year funding envelope for each of the priorities and activities outlined in the JCFD. Historically funding from New Zealand was given on an annual basis, which does not give great certainty for Niue in terms of forward planning. "The FAP is great because we have a bit more certainty with it now. We can plan things ahead in 3 years. But also the budget is flexible. We can move monies from sector to sector and from year to year. We decide how much we can spend on the first, second and final year subject to discussions with New Zealand. But it's not hard like it used to be" (Respondent $\mathrm{H})$.

Respondent F further states that the "flexibility has allowed us to achieve a lot more things, because some things didn't really become apparent initially, but only after we started down the path before we realised we needed other things, so that was very helpful". 
Requesting for changes within the budget was a dreaded task, "we always need to consult with New Zealand about making changes within the FAP and these are through variance reports. This is to ask to move monies within the budget from a one activity to assist with another activity. It used to be so difficult and very time consuming to get New Zealand's approval. But now it's much easier, we write them a letter with our intentions instead of writing a long proposal explaining the change, even if it's asking for a little change in the budget. I'm happy it's better now" (Respondent J). To complete, aid is disbursed and executed using the public financial management systems of the government of Niue (MFAT, 2016).

\subsubsection{Report and Review}

The current aid system recipients are highly accountable to the donors yet donors are rarely accountable to the recipient governments. Niue has never questioned New Zealand with regards to its policy changes and the implications on Niue, respondent E summarises this inability to question as "You don't bite the hand that feeds you". How do you maintain transparency when you cannot inquire? Respondent F says "when you're spending somebody else's money you got to jump to their tune. That's what we realised way back you learn very quickly in terms of the NZAID budget, they have got people to answer to, they don't want to see their money wasted, we don't either. We like to account for the money we get, how that money's given always changes over time. The relationship now is a lot different than it was then". 
The FAP and the JCFD are highly valued and used by the government of Niue as a planning tool. The reporting of activities within the FAP has been an ongoing issue and extensive consultations has gone into finding practical ways to improve or lessen the reporting requirement from departments. Chapter 6 concluded that the biggest hurdle for the government is changing the attitudes and behaviours of public servants and their outlook on development. "One of the biggest problems is trying to get the departments to account for the money they got. We're constantly running around trying to get these people to file a report, because if we don't it's gonna reflect poorly on us and it impedes on us going knocking on the door for more money. What we didn't realise is what we're doing is counterproductive, we're like shooting ourselves in the foot. When we're going to departments to do this, we were targeted as going against the government departments. Some of our worst performers were the loudest critics" (Respondent F).

As part of a review of the JCFD, a results framework was led by New Zealand to monitor the performance of the commitments outlined in the framework and the progress of its intended results. The review was not an easy, collecting the data and progress because the JCFD from the beginning was not fully understood by Niue government officials. Overall, significant improvements have been made, the load is manageable for Niue officials "It's usually a monthly reporting on the activities but now it's three monthly, so it's better'" (Respondent $\mathrm{H}$ ). 


\subsection{Summary}

The Paris Declaration has proved to be useful in Niue with regards to the NZAID programme. New Zealand have made changes in its programme to support Niue and its development. The FAP has played a major role in simplifying and streamlining what used to be a very complex task between donor and recipient. It has given Niue more flexibility in planning for long term compared to the annual funds that was previously given by New Zealand aid. The flexibility has enabled Niue to achieve a lot more than it used to. The working relationship between officials of New Zealand and Niue are much more open and free. Government officials of Niue are no longer anxious to agree or disagree with decisions on activities concerning them. They can communicate openly and freely. The JCFD has provided a simplified approach for Niue and New Zealand to work towards achieving the vision in Niue's national strategic plan for a prosperous Niue. It was not initially welcomed by Niue officials, because it was not designed and managed by Niue. A lot more consultations with the wider government officials of Niue were required in order for better results. I believe the greatest accomplishment of the JCFD was holding New Zealand mutually accountable for all the commitments. Despite the rhetoric of promoting ownership and building capacity the pressure is usually too great to get quick results ( , 2011). With this, New Zealand will need to be more understanding, while Niue will need to focus on its obligation in ensuring reports are submitted on time. 


\section{CHAPTER 8: PARIS IN NIUE - CONCLUSION}

\subsection{Introduction}

The last three chapters presented the findings of the research, chapter 5 analysed the Paris Declaration Principles of ownership, alignment, harmonisation and mutual accountability in practise in Niue. Chapter 6 presented the common issues the respondents recognised that were hampering the development in Niue. Chapter 7 was slightly different because it presented the relationship between the government of Niue and the government of New Zealand, and analysed using the Paris principles. To recap the aim of this research is to investigate the influence of the aid effectiveness agenda in Niue's development, and the objectives to guide the research were:

1. To what extent are the Paris Declaration Principles of ownership, alignment, harmonisation and mutual accountability practised in Niue?

2. How effectively does the NZAID programme apply the Paris Declaration principles in its relationship with Niue?

3. What ways can the Government of Niue improve or strengthen its aid relationships internally and externally?

This chapter will combine all the findings in chapters 5 to 7 , placing these findings against the aid effectiveness agenda in chapters 3 and 4 . 


\section{2 (Im) Proving Paris in Niue}

The Paris forum was recognised as history for development assistance and cooperation. The Paris declaration was built on many of the negative lessons and projects over the years. The shift towards aid that gives the recipient country the power to make decisions and priorities they set. The five principles of the Paris declaration accompanied with the 13 targets was the target for tracking progress over 5 years. Although there were recognised improvements the level of compliance of the targets was said to be slow with only one of the 13 targets achieved (OECD, 2012). The Paris declaration have gained ground and made positive changes in Niue. There is strong ownership in Niue developing its strategies. A lot of improvement is required on the implementation side, in order for Niue to fully have ownership. Niue struggles with competing priorities. This has made it difficult to fix on one priority and work toward its progress. The government priorities are sometimes manipulated by development donors when the donors advertise new funding. The government of Niue changes its priorities to suit the package advertised in order to receive the funding. At times development donors need to adopt and promote coherent and responsible behaviours by empowering country government. The Paris declaration places equal emphasis on both the need for donors to align to country policies and systems, and for recipient countries to improve their systems through joint commitments to capacity building and support (Foresti et al, 2006).

The level of alignment varies for the government of Niue. This was recognised and the government made efforts towards improvement after a recommendation of the NNSP 2009-2013 review. A working committee was 
established to find ways for government to better enhance its processes and systems of alignment. What came out from this was the new format corporate plan for all departments to use. The purpose was to streamline all the plans and make it easy for monitor and review.

\subsection{Next Steps for the Government of Niue}

The development landscape is changing and the lessons of the Paris declaration have helped Niue develop and encourage better ways of working together to benefit everyone. It is through the promotion of open dialogue between all stakeholders of the government. The government can improve its aid relationship by setting up mechanisms to manage the relations between different departments and keep these departments accountable for their duties and commitments.

\subsubsection{Manage department relations}

The mechanisms important to manage department relations are confidence, credibility, coherence and capacity. Confidence in relationships between government departments must be based on reciprocal trust and confidence. This is achievable when departments interact and demonstrate good faith. Credibility in department engagement needs to be structured by clear and credible frameworks. The credibility comes from long-term vision when priorities are clearly articulated. Coherence is achieved when departments have on-going dialogue, on-going negotiations and ultimately achieve their goals. There is a need for a structured dialogue for government stakeholders a way that promotes confidence and trust. 
Inconsistencies with other departments will limit the government's ability to improve and encourage behavioural change. Coherence also requires a strong coordination from the Niue Public Service Commission (NPSC). It is important that strong coordination comes from the NPSC because they have general oversight and control of departments and management. They are also responsible for reviewing the efficiency and economy of all departments and offices of the executive government (Niue Constitution, 1974).

\subsubsection{Foster Recipient-government Led Forums}

The Pacific Islands Forum Secretariat have attempted cross-country learning and exchange between Pacific islands because country-level mechanisms have existed independently. This is important to share lessons from those with more advanced mechanisms. The knowledge of the Paris Declaration is much stronger within donor agencies than it is in recipient governments. Knowledge of the Paris Declaration is still limited to the few government officials that has the most interaction with the donor community. There is a lack- of an international recipient country forum where recipient governments learn from each other, negotiate their positions around aid effectiveness and have a common view and position to approach development donors. These discussions can range from capacity constraints and lack of resources which is common in Niue. Discussions also around alternatives to aid as recipient governments when not following donor procedures fear the withdrawal of donor funding. Most importantly to improve knowledge and awareness on development aid overall. Therefore a recipient led forum is important because it will provide recipient governments a place to meet and develop a collective 
response to donor policies, practise and behaviour hence creating stronger incentives for aid reform.

\subsubsection{Invest in Aid Management}

Niue needs to put more focus on monitoring and evaluation of its plans. If the designated department is not working then focus on moving the responsibility to a well-equipped department who is able to carry the duties. The monitoring and review processes would maximise involvement and empowerment of domestic accountability. Niue needs to invest in capacity building for aid management, supporting government departments in charge of aid coordination with adequate means and capacity to better negotiate with donors. The capacity to develop, manage and monitor policies as well as procedures for aid management is a key constraint for the Niue government. This capacity extends towards political, the capacity to understand and negotiate better and not only to delegate or manage. In some parts, to reduce economic vulnerability Niue will need to further strengthen its private sector. This can be through the establishing economic linkages with other agencies in the tourism industry outside of Niue. Ultimately, building capacity is crucial for Niue in order to reap the potential benefits.

\subsection{Conclusion}

There are many challenges associated with implementing the Paris principles. But the central question here is, has it worked for Niue? Simply put, yes it has!

The relationship between the government of Niue and the government of New Zealand is now labelled a partnership highlighting mutual and equal partners. 
A far cry from the 'excessive bureaucracy and bully-boy tactics' in the 1990s. The officials from the Niue government were pleased with the working relationship between officials of both governments. Dialogue is more open and ideas are more accepted from the Niue side. The Niue officials feel they now have a voice around the negotiating table. 'But beneath this veneer of prosperity a disturbing and potentially destabilising trend was emerging: Niueans were migrating to New Zealand' (Pointer, 2016, p 308).

Although massive improvement and positive outcomes is seen in the relationship with the New Zealand government, a bleak result exists within the Niue government. The transformation process of the government has not demonstrated the expected results. In some cases it has exacerbated negatively. For example, the office for external affairs is the Niue government's official point of contact for international donor agencies. To some extent the work of the office has been less clearly defined in the absence of an official policy on foreign relations (GON, 2009). And following the transformation which was supposed to provide a coordinated approach has done the total opposite, created more confusion and more misunderstanding. A strong internal focus on governments systems, resources and relationships is really needed. Systems requirement refers to the approaches, tools and technologies to bring about improvements in the government. An example of systems improvement is attaining ISO 9000 for quality management certification and standards. A suggestion because if the department for meteorology can achieve ISO standards, then other departments can also follow. This will help the departments build new systems and strengthen 
existing ones. A focus on resources here is directed at man power, the most important resources of the Niue government. The government needs to provide or establish a platform for the people to express their views and opinions on issues relating to the development of Niue, with no implications but an open and free forum. This will then lead to relationship building within government and between government and people.

History has borne inadequate outcomes, but simple and small steps can make effective changes. A wealth of a nation should be evaluated in accordance with how the citizens of the country sees it. Development views have been heavily influenced by macroeconomics and macro politics. Not all donors have strong geopolitical interests, but all of them have trade interests. A donor's foreign assistance policy is based on its self-interest and typically will be biased toward countries that tend naturally to have more trade with it. This is the motive of tied aid which persists in spite of continuous efforts from the OECD/DAC to reduce it. The New Zealand government have had many concerns about Niue, in the Hayes 2010 report presented to the House of Representatives identified Niue as reaching a point where Niue should accept that it can never be a sustainable economic entity (Hayes, 2010). This concern further extends to Niue's constitutional viability as the population continues to decline. Although New Zealand government needs to acknowledge and take responsibility that the changing policies of its government also affected Niue. Therefore a concerted effort from both governments is needed to fully achieve the principles of the Paris declaration. 


\subsection{Further Research}

More research must be undertaken in order to understand the impact of the aid effectiveness agenda. A critical area is research from the recipient government's perspective, to fully articulate the realities recipient governments go through, because foreign aid merely promotes dependency of recipients by some academics. Among academia studies view foreign aid as furthering dependency assuming that aid mostly facilitates the donor's interests. It undermines the economy, the social fabric and accountability to recipients, this is why further research should be done at this area to enable recipient governments with instruments that can educate and support them. There is broad agreement by recipient governments, development donors and civil society that further progress is necessary and that what happens at country level needs to be complemented by mechanisms at the international level (OECD, 2012).

\subsection{Final Reflection}

At the start of the thesis, I had a fair idea of what results I was going to receive from my field work owing to my previous work experience in the Niue government. Surprisingly my pre-determined conclusions were shattered completely. I went in thinking that the big development donor is the bully and needed to change its ways to accommodate its recipient country. I was surprised that it was actually the opposite, NZAID have improved its systems and are more flexible for Niue. The problem lies within the Niue government, and getting the aid architecture right heading into the future. This is crucial and this will require challenging the status quo. It is admirable that Niue is taking charge of its development strategies even if it is taking longer than 
expected; even if it is not presenting optimistic results. The Government of Niue has come a long way and have dealt with the challenges. The Niue government has ownership in planning and making its development strategies but in practice and these strategies are weak. There is repetition of activities for projects that could be eliminated and efforts made more effective. There is a need to develop positive relationships. Communication and respect are key to effective working relationships and this trust needs to come from the high level. A holistic approach is important to economic development. This holistic approach means incorporating all sectors that is outside of the government network, for strategic planning processes. Niue has come a long way, and still has a long way to go but it is reassuring to know that the government have made steps towards is development vision of,

"Niue Ke Monuina - A Prosperous Niue". 


\section{APPENDIX ONE - Interview Guide}

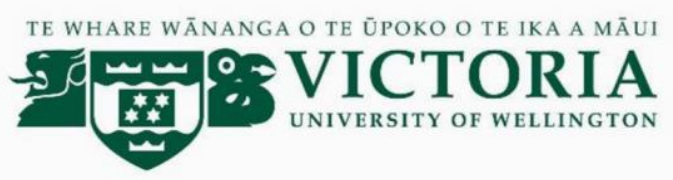

Paris in Niue: An Analysis of the Aid Effectiveness Agenda in Niue Interview Questions:

1. What is your position, and how long have you been in this position?

2. What are your key roles within the Government?

3. Who are the key development partners you work with?

4. Approximately how many development partner officials have come through your office in the past 6 months?

5. Do you think development partners use GON systems?

6. How often are you required to travel overseas for donor/project requests?

7. How is the relationship between GoN and donors working?

8. How often do you work on NZAID related matters?

9. Are you involved in the biannual negotiations between the government and NZAID?

10. Do you think NZAID aligns its programme with GONs priorities?

11. How can the relationship between Niue and NZAID be improved?

12. What are your views of the newly established Projects Management Unit? 


\section{APPENDIX TWO - Information Sheet}

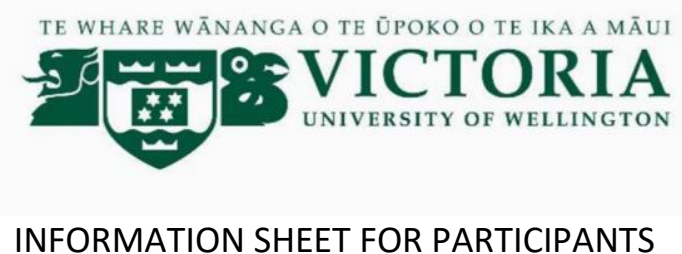

Thank you for your interest in this project. Please read this information before deciding whether or not to take part. If you decide to participate, thank you. If you decide not to take part, thank you for considering my request.

Who am I?

My name is Felicia Talagi and I am a Masters student in Development Studies at Victoria University of Wellington. This research project is work towards my thesis.

What is the aim of the project?

This project is looking at how the Government of Niue (GON) manages its aid programme from NZ.

Essentially, I am researching the relationship and ways this relationship can be strengthened. This research has been approved by the Victoria University of Wellington Human Ethics Committee [provide approval number].

How can you help?

If you agree to take part I will interview you in a place that is comfortable for you. I will ask you questions about your work (either projects or policies) with donor partners or government officials. The interview will take approximately 30 minutes. I will record the interview and write it up later. You can stop the interview at any time, without giving a reason. You can withdraw from the study up to four weeks after the interview. If you withdraw, the information you provided will be destroyed.

What will happen to the information you give?

This research is confidential. I will not name you in any reports, and I will not include any information that would identify you. Only my supervisors and I will read the notes or transcript of the interview. The interview transcripts, summaries and any recordings will be kept securely and destroyed [5] years after the research ends. 
What will the project produce?

The information from my research will be used in my Masters thesis. You will not be identified in my report. I may also use the results of my research for conference presentations, and academic reports. I will take care not to identify you in any presentation or report.

If you accept this invitation, what are your rights as a research participant?

You do not have to accept this invitation if you don't want to. If you do decide to participate, you have the right to:

- $\quad$ choose not to answer any question;

- $\quad$ ask for the recorder to be turned off at any time during the interview;

- $\quad$ withdraw from the study up until four weeks after your interview;

- $\quad$ ask any questions about the study at any time;

- $\quad$ read over and comment on a written summary of your interview; • be able to read any reports of this research by emailing the researcher to request a copy.

If you have any questions or problems, who can you contact?

If you have any questions, either now or in the future, please feel free to contact either:

Student: Supervisor:

Name: Felicia Talagi Name: Professor John Overton University email address: School: Environment, Geography talagifeli@myvuw.ac.nz \& Earth Sciences

John.Overton@vuw.ac.nz

Human Ethics Committee information

If you have any concerns about the ethical conduct of the research you may contact the Victoria University HEC Convener: Associate Professor Susan Corbett. Email susan.corbett@vuw.ac.nz or telephone +64-4-463 5480. 


\section{APPENDIX THREE - Consent Form}

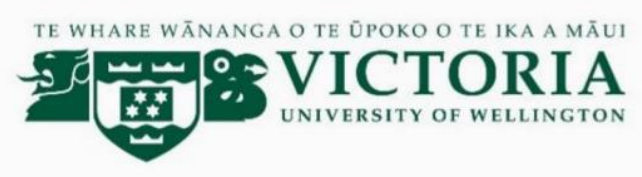

An Analysis of the Aid Effective Agenda in Niue

CONSENT TO INTERVIEW

This consent form will be held for [5] years.

\section{Researcher: Felicia Talagi}

- I have read the Information Sheet and the project has been explained to me. My questions have been answered to my satisfaction. I understand that I can ask further questions at any time.

- I agree to take part in a recorded interview.

I understand that:

- I may withdraw from this study up to [four weeks] after the interview [or, by specified date], and any information that I have provided will be returned to me or destroyed.

The information I have provided will be destroyed [3] years after the research is finished.

- $\quad$ Any information I provide will be kept confidential to the researcher and the supervisor. I understand that the results will be used for an Masters report and a summary of the results may be used in academic reports and/or presented at conferences.

- $\quad$ My name will not be used in reports, nor will any information that would identify me. 
- $\quad[O R]$ I consent to information or opinions which I have given being attributed to me in any reports on this research: Yes No

- I would like a copy of the transcript of my interview: Yes No

- I would like a summary of my interview: Yes No

- I would like to receive a copy of the final report and have added my

Signature of participant:

Name of participant:

Date:

Contact details: 


\section{REFERENCES}

ADB. (2011). The Millennium Development Goals in Pacific Island Countries. Manila: Asian Development Bank.

Akyar, I. (2012). Standard Operating Procedures (What Are They Good For?). INTECH Open Access Publisher.

Altheide, D. L., \& Johnson, J. M. (1994). Criteria for assessing interpretive validity in qualitative research. In Handbook of Qualitative Research (p485499). California: Sage

Alesina, A., \& Weder, B. (1999). Do corrupt governments receive less foreign aid? American Economic Review 92(4), 1126-1137.

Alesina, A. \& Dollar, D. (2000). Who gives foreign aid to whom and why? Journal of Economic Growth, 5(1), 33-63.

Alvesson, M. \& Sköldberg, K. (2009). Reflexive Methodology: New Vistas for Qualitative Research. London: Sage.

Angelo, T. (2002). To be or not to be ... integrated, That is the problem of islands. Revue Juridique Polynesienne 2 87-108

Angelo, T. (2004). A few comparative remarks on the concept of free association in the South Pacific. mimeo. Wellington: Victoria University of Wellington. Retrieved from:

http://www.victoria.ac.nz/law/research/publications/about-

nzacl/publications/special-issues/hors-serie-volume-iv,-2004/Angelo.pdf

Aqorau, T. (2006). Rethinking Sovereignty in the Pacific. Pacific Islands Development Program/East-West Centre. Honolulu: University of Hawai'i: Center for Pacific Islands Studies.

Armon, J. (2007). Aid, politics and development: A donor perspective. Development Policy Review, 25(5), 653-656.

AusAID. (2006). Pacific 2020, Challenges and Opportunities for Growth. Canberra: Pirion.

Banks, G., Murray, W., Overton, J. and Scheyvens, R. (2012). Paddling on one side of the canoe? The changing nature of New Zealand's development assistance programme. Development Policy Review, 30: 169-186.

Barder, O. (2009). What is Poverty Reduction? .CDG Working Paper 170. Washington D.C: Center for Global Development. 
Barnett, J, \& Ellemor, H. (2007). Niue after Cyclone Heta. Australian Journal of Emergency Management, 22(1), 3.

Barnett, J. (2008). The effect of aid on capacity to adapt to climate change: Insights from Niue. Political Science, 60(1), 31-45.

Bertram, G. (1999). The MIRAB Model Twelve Years On. The Contemporary Pacific, 11(1), 105-138.

Bertram, G., \& Watters, F. (1985). The MIRAB economy in South Pacific microstates. Pacific Viewpoint, 26(3) 497-519.

Bertram, G. (1993). Sustainability, aid and material welfare in small South Pacific island economies. World Development, 21(2), 247-258

Berthélemy, J. C. (2006). Bilateral donors' interest vs. recipients' development motives in aid allocation: do all donors behave the same? Review of Development Economics, 10(2), 179-194.

Bonner, A., \& Tolhurst, G. (2002). Insider-outsider perspectives of participant observation. Nurse researcher, 9(4), 7-19.

Booth, D. (2012). Aid effectiveness: bringing country ownership (and politics) back in. Conflict, Security \& Development, 12(5), 537-558.

Boone, P. (1996). Politics and the effectiveness of foreign aid. European Economic Review, 40(2), 289-329.

Bourke, B. (2014). Positionality: Reflecting on the research process. The Qualitative Report, 19(33), 1-9.

Brautigam, D. (2000). Foreign aid and the politics of participation in economic policy reform. Public Administration \& Development, 20(3), 253.

Brien, D. (2013). How to Win Friends and Influence Policy. Pacific Institute of Public Policy. Retrieved from: http://www.pacificpolicy.org/2013/12/howto-win-friends-and-influence-policy/

Breen, L. J. (2007). The researcher 'in the middle': negotiating the insider/outsider dichotomy. Special Edition Papers, 19(1), 163-174.

Brohman, J. (1996). Popular Development: Rethinking the Theory and Practice of Development. Oxford: Wiley-Blackwell.

Burnside, C. \& Dollar, D. (2000). Aid, policies, and growth. American Economic Review, 90(4), 847-868.

Bryman, A., \& Burgess, R. G. (1999). Qualitative Research. Methods of Qualitative Research. London: Sage. 
Bryman, A. (2004). Qualitative research on leadership: A critical but appreciative review. The leadership quarterly, 15(6), 729-769.

Canales, M. K. (2000). Othering: Toward an understanding of difference. Advances in Nursing Science, 22(4), 16-31.

Cassen, R. (1994). Does aid work? Report to an Intergovernmental Task Force. Study Preparation for a Meeting of the Task Force. New York: Clarendon Press.

Chambers, R. (1997). Whose Reality Counts? Putting the First Last. London: Intermediate Technology Publications Ltd (ITP).

Chapman, T. M. (1976). The decolonisation of Niue. Wellington: New Zealand Institute of International Affairs.

Chacko, E. (2004). Positionality and Praxis: Fieldwork Experiences in Rural India. Singapore Journal of Tropical Geography, 25(1), 51-63.

Clark, D. P. (1992). Distributions of official development assistance among developing country aid recipients. The Developing Economies, 30(3), 189197.

Clemens, M. A., Radelet, S., \& Bhavnani, R. R. (2004). Counting chickens when they hatch: The short term effect of aid on growth. Center for Global Development Working Paper No. 44

Collier, P. (2008). The Bottom Billion: Why the Poorest Countries are Failing and What Can be Done About It. New York: Oxford University Press.

Connell, J. (2007). 'The Best Island on the Globe': Constantly constructing tourism on Niue. Australian Geographer, 38(1), 1-13.

Costley, C., Elliott, G. C. \& Gibbs, P. (2010). Doing Work Based Research: Approaches to Enquiry for Insider-Researchers. London: Sage.

Deutscher, E. \& Fyson, S. (2008). Improving the effectiveness of aid. Finance and Development, 45(3), 15-19.

Deutscher, E. (2009). Committing to effective aid: Why can't donors walk their talk? Development Outreach, 11(1), 6-10.

De Renzio, P., Booth, D., Rogerson, A, \& Curran, Z. (2005). Incentives for Harmonisation and Alignment in Aid Agencies. A Report to the DAC Working Party on Aid Effectiveness. London: Overseas Development Institute.

De Renzio, P., \& Mulley, S. (2006). Promoting Mutual Accountability in 
Aid Relationships: Addressing the Power Imbalance between Donors and Recipients is Necessary to Promote Real Partnerships. ODI Briefing papers, London: Overseas Development Institute.

DFAT. (2006). Pacific 2020. Challenges and Opportunities for Growth. Canberra: Public Affairs Group. AusAID.

DeLyser, D. (2001). "Do you really live here?” Thoughts on Insider Research. Geographical Review, 91(1_2), 441-453.

Domingo, P., Wild, L., Hudson, A., \& Wathne, C. (2009). Domestic and Mutual Accountability for Aid: Building Stronger Synergies Literature Review and Conceptual Framework. London: Overseas Development Institute for the Commonwealth Secretariat.

Dutton, J. E., \& Ashford, S. J. (1993). Selling issues to top management. Academy of Management Review, 18(3), 397-428.

Easterly, W. (2006). Planners versus searchers in foreign aid. Asian Development Review, 23(2), 1.

Easterly, W. (2006). The white man's burden: Why the West's efforts to aid the rest have done so much ill and so little good. The Independent Review, 11(4), 616-619.

Ejimabo, N. O. (2015). The effective research process: Unlocking the advantages of ethnographic strategies in the qualitative research methods. European Scientific Journal, 11(23).

Feeney, S., \& McGillivray, M. (2010). Aid and growth in small island developing states. The Journal of Development Studies, 46(5), 897-917.

Field, P. A. (1991). Doing fieldwork in your own culture. Qualitative Nursing Research: A Contemporary Dialogue (91-104). London: Sage

Floyd, S. W., \& Wooldridge, B. (1996). The strategic middle manager: How to create and sustain competitive advantage. Jossey-Bass Publishers.

Foresti, M., Booth, D., \& O’Neil, T. (2006). Aid Effectiveness and Human Rights: Strengthening the Implementation of the Paris Declaration. ODI report to the DAC. London: Overseas Development Institute

Gani, A. (2006). Pacific Island countries high per capita foreign aid requirement. Journal of International Development 18(2) 285-292.

Ganga, D. \& Scott, S. (2006). Cultural insiders and the issue of positionality in qualitative migration research: Moving across and moving along researcher-participant divides. Forum: Qualitative Social Research 7(3). 
Gegeo, D. W. \& Watson-Gegeo, K. A. (2001). "How we know": Kwara'ae rural villagers doing indigenous epistemology. The Contemporary Pacific, 13(1), 55-88.

Gerrish, K., \& Lacey, A. (2010). The Research Process in Nursing. Sussex: John Wiley \& Sons.

Graham, C., \& O'Hanlon, M. (1997). Making foreign aid work. Foreign Affairs, 76(4) 96-104.

Goldsmith, M. (2015). The Big Smallness of Tuvalu. Global Environment, $8(1), 134-151$.

GON. (2003). Niue Island Strategic Plan 2003-2008. Alofi: Government of Niue.

GON. (2005). Niue Merchandise Trade. Statistical Release. Economic, Planning, Development and Statistical Unit. Alofi: Government of Niue.

GON. (2004). National Impact Assessment Report of Cyclone Heta.

Economic, Planning, Development and Statistics. Alofi: Government of Niue.

GON. (2007). Niue Private Sector Development Strategic Plan 2007-2010. Alofi: Government of Niue.

GON. (2009). Niue National Strategic Plan 2009-2013. Alofi: Government of Niue.

GON. (2009). Office for External Affairs Corporate Plan 2009-2013. Alofi: Government of Niue

GON. (2016). Niue Trade Issues. Alofi:Government of Niue.

Hall, S. (1990). Cultural identity and diaspora. In J. Rutherford (Ed.), Identity: Community, Culture, Difference (pp., 2-27). London: Lawrence \& Wishart.

Hayes, J. (2010). Inquiry into New Zealand's relationships with South Pacific Countries. Presented to the House of Representatives, Forty-Ninth Parliament.

Hauofa, E. (1993). A New Oceania: Rediscovering our Sea of Islands. School of Social and Economic Development. Suva: The University of the South Pacific

Hewitt-Taylor, J. (2001). Use of constant comparative analysis in qualitative research. Nursing Standard, 15(42), 39-42. 
Hewitt-Taylor, J. (2002). Inside knowledge: Issues in Insider Research. Nursing Standard, 16(46), 33-35.

Hughes, H. (2006). Trade, aid and development. Australian Economic Review, 39(1), 63-68.

Hughes, H. (2010). Aid has failed the Pacific. Pacific Economic Bulletin, 25(3), 232-234

Hyden, G. (2008). After the Paris Declaration: Taking on the issue of power. Development Policy Review, 26(3), 259-274.

James, C. (2014). Vested Interests. Working Paper No: 14/02. Institute for Governance and Policy Studies, Wellington, Victoria University of Wellington.

Jacobson, T. L., \& Servaes, J. (Eds.). (1999). Theoretical Approaches to Participatory Communication. Cresskill, NJ: Hampton Press.

Jong, J., Megens, I., \& van der Waal, M. (Eds.) (2011). Walking the Tightrope: Europe between Europeanisation and Globalisation: Selected papers presented at European studies intensive programme, University of Groningen. Groningen: Euroculture Consortium.

Kanuha, V. K. (2000). "Being" native versus "going native": Conducting social work research as an insider. Social Work, 45(5), 439-447.

Killick, T. (1997). Principals, agents and the failings of conditionality. Journal of International Development, 9(4), 483-495.

Kharas, H., \& Chandy, L. (2011). Measuring for Success at the Busan High Level Forum on Aid Effectiveness. Washington DC: The Brookings Institution.

Lancaster, C. (2007). Foreign Aid. Diplomacy, Development, Domestic Politics. Chicago and London: The University of Chicago Press. Lehman, B. J., \& Crano, W. D. (2002). The pervasive effects of vested interest on attitude-criterion consistency in political judgment. Journal of Experimental Social Psychology, 38(2), 101-112.

Leonard, D., \& Straus, S. (1997). Putting your company's whole brain to work. Harvard Business Review, 75, 110-122.

Lensink, R., \& White, H. (2001). Are there negative returns to aid? Journal of Development Studies, 37(6), 42-65.

Lingnau, H., \& Sattelberger, J. (2015). Making partnerships effective coalitions for action. Paris: Organisation for Economic Cooperation and Development (OECD). Retrieved from 
http://search.proquest.com/docview/1714457846?accountid=14782

Liuvaie, S. F. (2009). Investigating Impediments to Aid Effectiveness: New Zealand's Development Assistance to Niue'. In R. Gounder (Ed.), Pacific Development Perspectives: Meeting our Diverse Goals (pp. 142-90). Palmerston North: Massey University.

Maslach, C., \& Goldberg, J. (1999). Prevention of burnout: New perspectives. Applied and Preventive Psychology, 7(1), 63-74.

McGillivray, M. (2004). Is aid effective? Helsinki: World Institute for Development Economics Research (mimeo).

McGee, R., \& Heredia, I. G. (2012). Paris in Bogotá: The aid effectiveness agenda and aid relations in Colombia. Development Policy Review, 30(2), $115-131$.

Melkote, S. R. (2000). Redeveloping Communication for Social Change. Theory, Practice and Power. (39) Lanham, Maryland: Rowman and Littlefield Publishers.

MFAT. (2012). Partnerships in Progress - Development in the Pacific. Wellington: Ministry of Foreign Affairs and Trade.

MFAT. (2016). Aid Partnership with Niue. Retrieved from New Zealand Foreign Affairs and Trade: https://www.mfat.govt.nz/en/aidanddevelopment/our-work-in-the-pacific/aid-partnership-with-niue/

Miller, D. T. (1999). The norm of self-interest. American Psychologist, 54(12), 1053.

Mosley, P. (1986). Aid _ effectiveness: The micro-macro paradox. IDS Bulletin, 17(2), 22-27.

Morss, E. R. (1984). Institutional destruction resulting from donor and project proliferation in Sub-Saharan African countries. World Development, 12(4), 465-470.

Moyo, D. (2009). Dead Aid. Why Aid is Not Working and How There is a Better Way for Africa. New York: Allen Lane, Penguin Books

Murray, W. E., \& Overton, J. (2011). The inverse sovereignty effect: Aid, scale and neostructuralism in Oceania. Asia Pacific Viewpoint, 52(3), 272284.

Murray, W. E., \& Overton, J. (2003). Designing Development Research. Development fieldwork a practical guide, London: Sage.

Murray, W. E., \& Overton, J. (2011). Neoliberalism is dead, long live neoliberalism? 
Neostructuralism and the international aid regime of the 2000s. Progress in Development Studies, 11(4), 307-319.

Murray, W. E., \& Overton, J. (2016). Retroliberalism and the new aid regime of the 2010s. Progress in Development Studies, 16(3), 244-260.

Ncayiyana, D. J. (2007). Combating poverty: the charade of development aid. British Medical Journal, 335(7633), 1272-1273.

Nelson, E. A. S. (1994). Development aid: the way forward. British Medical Journal, 308(6926), 481.

New Zealand Agency for International Development (NZAID). (2010). FAQs: Recent changes to NZAID. Online retrieved from: http://www.nzaid.govt.nz/faqs/recent-changes-to-nzaid.html

New Zealand Agency for International Development (NZAID). (2009). New Zealand's aid programme - an overview. Online, retrieved from http://www.nzaid.govt.nz/library/ docs/factsheet-nzaid-overview.pdf

Niue Constitution (1974). The Constitution of Niue. Alofi: Government of Niue.

OECD. (2003). The Rome Declaration on Harmonisation. Paris: OECD

OECD. (2005). The Paris Declaration on Aid Effectiveness. Paris: OECD

OECD. (2008). Paris Declaration on Aid Effectiveness and the Accra Agenda for Action. Paris: OECD.

OECD. (2011). Busan Partnership for Effective Development Cooperation. Paris: OEDC

OECD. (2012). Aid Effectiveness 2011: Progress in Implementing the Paris Declaration. Paris: OECD

OECD. (2015). Oceania Development Aid at a Glance. Online retrieved from http://www.oecd.org/dac/stats/aid-at-a-glance.htm

OECD. (n.d.). Accelerating Progress in Aid Effectiveness: From Here to 2011. Paris: OECD Working Party on Aid Effectiveness.

O'Leary, Z. (2004). The Essential Guide to Doing Research. London:Sage.

Overton, J., (2009). The aid industry in New Zealand. Journal of International Education and Business, 1 (1), pp. 27-48.

Overton, J., (2010). Aid: Pacific Perspectives. Victoria University of Wellington, New Zealand. 19 August 2010. Lecture Notes. 
Otsuka, S. (2005). Talanoa research: Culturally appropriate research design in Fiji. In International Education Research Conference, Melbourne.

Owa, M. (2015). Is OECD DAC's aid effectiveness agenda based on evidence? Journal of Development Effectiveness, 7(4), 435-444.

Pavlov, V., \& Sugden, C. (2006). Aid and growth in the Pacific Islands.

Crawford School of Economics and Government, ANU, 38-55.

PACC (2007). Niue Pacific Adaptation to Climate Change Water Sector Demonstration Project. Technical Report No. 14.Apia: Pacific Adaptation to Climate Change Project

PIFS. (2007). Pacific Aid Effectiveness Principles. Suva: Pacific Islands Forum Secretariat.

PIFS. (2005). Aid Effectiveness in the Pacific. Pacific Island

Countries/Development Partners Meeting, Funafuti: Pacific Islands Forum Secretariat.

PIFS. (2009). Cairns Compact On Strengthening Development Coordination in the Pacific. Suva: Pacific Islands Forum Secretariat.

PIFS (2013). Annual Report. Suva: Pacific Islands Forum Secretariat

PIFS. (2014). Effective Leadership, Institutions and Mutually Accountable Partnerships. 2014 Tracking the Effectiveness of Development Efforts in the Pacific Report. Suva: Pacific Islands Forum Secretariat.

Pointer, M. (2015). Niue 1774-1974. 200 Years of Contact and Change. Dunedin: Otago University Press

Poirine, B. (1999). A theory of aid as trade with special reference to small islands. Economic Development and Cultural Change, 47(4), 831-852.

Quentin-Baxter, A. (2008). The New Zealand model of free association: What does it mean for New Zealand. Victoria University of Wellington Law Review, 39(4), 607-634.

RNZI (2014). Niue four-day week continuing to Xmas. Retrieved from Radio New Zealand International:

http://www.radionz.co.nz/international/pacific-news/249768/niue-fourdayweek-continuing-to-xmas

Rakner, L., \& Wang, V. (2007). Governance Assessments and the Paris Declaration. A CMI Issues Paper Prepared for the UNDP Bergen Seminar. Chr. Michelsen Institute. 
Riddell, R. C. (2007). Does Foreign Aid Really Work? New York: Oxford University Press.

Rodgers, J. (2013). Small Islands, Big Challenges: Rethinking the Pacific Aid Architecture. Retrieved from Development Policy Centre: http://devpolicy.org/small-islands-big-challenges-rethinking-the-pacificaidarchitecture-20131023/

Rogerson, A. (2005). Aid harmonisation and alignment: Bridging the gaps between reality and the Paris reform agenda. Development Policy Review, 23(5), 531-552.

Rogers, E. M. (1976). Communication and development the passing of the dominant paradigm. Communication Research, 3(2), 213-240.

Sachs, J. (2014). Sustainable Development Economics. Project Syndicate. The Worlds Opinion Page. Retrieved from: https://www.projectsyndicate.org/commentary/promote-sustainable-develo pment- economicsby-jef rey-d-sachs-2014-11

Saili, C. (2013). Overview of development coordination and aid. Harmonisation Efforts in the Pacific. Health Development Partners Forum (p. 22). Suva: Pacific Islands Forum.

Scheyvens, R. \& Overton, J., (1995). Doing well out of our doing good: A geography of New Zealand aid. Pacific Viewpoint, 36 (2), pp. 195-210. Scott, D. (1993). Would A Good Man Die? Niue Island, New Zealand and the Late Mr Larsen. Auckland: Hodder and Stoughton

Scheyvens, R. (Ed.). (2014). Development fieldwork: A practical guide. London: Sage.

Smyth, A., \& Holian, R. (2008). Credibility Issues in Research from Within Organisations. Researching Education from the Inside. 33-47. London: Routledge

Sogge, D. (2002). Give \& Take. What's The Matter With Foreign Aid? London: Zed Books.

SPC (2009). Joint Country Strategy 2009-2013 in Supoort of Niue's National Strategic Plan 2009-2013. Noumea: South Pacific Community

Steer, L., Wathne, C., \& Driscoll, R. (2009). Mutual Accountability at the Country Level: A Concept and Emerging Good Practice Paper. London: Centre for Aid and Public Expenditure, Overseas Development Institute. 
Sultana, F. (2007). Reflexivity, positionality and participatory ethics: Negotiating fieldwork dilemmas in international research. ACME: An International Journal for Critical Geographies, 6(3), 374-385.

Tangi. B (2012). Is Aid Effective in the Pacific. Global Burden on Surgical Diseases Conference. Melbourne.

Thaman, K. (2003). Decolonizing Pacific Studies: Indigenous Perspectives, Knowledge, and Wisdom in Higher Education. The Contemporary Pacific, 15(1), 1-17.

Thaman, K. H. (1992). Cultural Learning and Development through Cultural Literacy. Voices in a Seashell: Education, Culture and Identity, 2436.

Townend, A. (2003). The strange death of the realm of New Zealand: the implications of a New Zealand republic for the Cook Islands and Niue. Victoria University Wellington Law Review. 34(3), 571-608.

Tujan, A. (2012). Message from the Better Aid Co-Chairs announcing the dissolution of Better Aid, 21 December 2012. Retrieved 30 August 2016 from http://betteraid.org/

Ulu, A. J. (2013). Pule: Development Policy Sovereignty in Samoa. Wellington: Masters Thesis Victoria University of Wellington.

UNFPA. (2014). Population and Development Profiles: Pacific Island Countries. Suva: Pacific Sub-Regional Office, United Nations Population Fund.

Unluer, S. (2012). Being an insider researcher while conducting case study research. The Qualitative Report, 17(29), 1.

Vaioleti, T. (2013). Talanoa: Differentiating the talanoa research methodology from phenomenology, narrative, kaupapa Maori and feminist methodologies. Te Reo, 56, 191.

Vaioleti, T. M. (2016). Talanoa research methodology: A developing position on Pacific Research. Waikato Journal of Education, 12(1): 21-35.

Wesley-Smith, T. (1999). Decolonising Methodologies Research and Indigenous People. Dunedin: University of Otago Press.

White, S. C. (1996). Depoliticising development: the uses and abuses of participation. Development in Practice, 6(1), 6-15.

Wilkins, K. G., \& Mody, B. (2001). Reshaping development communication: Developing communication and communicating development. Communication Theory, 11(4), 385-396. 
Winters, M. S. (2012). The obstacles to foreign aid harmonization: Lessons from decentralization support in Indonesia. Studies in Comparative International Development, 47(3), 316-341.

Wrighton, N. (2010). Participation, Power and Practice in Development: A Case Study of Theoretical Doctrines and International Agency Practice in Tuvalu. Wellington: Masters Thesis, Victoria University of Wellington. 